\title{
Quasi-Spherical Ice in Convective Clouds $\mathscr{O}$
}

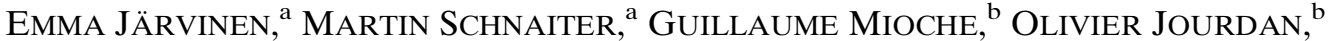 \\ VALERY N. SHCHERBAKOV, ${ }^{\mathrm{b}}$ ANJA COSTA, ${ }^{\mathrm{c}}$ ARMIN AFCHINE, ${ }^{\mathrm{c}}$ MARTINA KRÄMER, ${ }^{\mathrm{c}}$

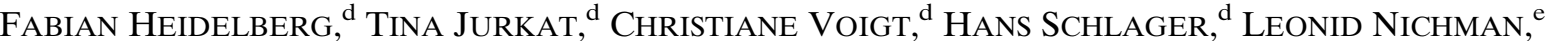

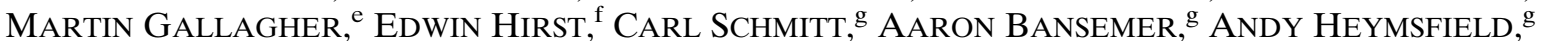 \\ Paul Lawson, ${ }^{\mathrm{h}}$ Ugo Tricoli, ${ }^{\mathrm{i}}$ Klaus PfEIlsticker, ${ }^{\mathrm{i}}$ PAUl Vochezer, ${ }^{\mathrm{a}}$ OTTMAR MÖHLER, ${ }^{\mathrm{a}}$ \\ AND THOMAS LEISNER ${ }^{\mathrm{a}}$ \\ ${ }^{a}$ Institute of Meteorology and Climate Research, Karlsruhe Institute of Technology, Karlsruhe, Germany \\ ${ }^{\mathrm{b}}$ Laboratoire de Métérologie et Physique, Clermont-Ferrand, France \\ ${ }^{\mathrm{c}}$ Stratosphere Section (IEK-7), Institut für Energie und Klimaforschung, Forschungszentrum Jülich, Jülich, Germany \\ ${ }^{\mathrm{d}}$ Deutsches Zentrum für Luft- und Raumfahrt (DLR), Oberpfaffenhofen, Germany \\ ${ }^{\mathrm{e}}$ School of Earth, Atmospheric and Environmental Sciences, University of Manchester, Manchester, United Kingdom \\ ${ }^{\mathrm{f}}$ Centre for Atmospheric and Instrumentation Research, University of Hertfordshire, Hatfield, United Kingdom \\ ${ }^{\mathrm{g}}$ National Center for Atmospheric Research, Boulder, Colorado \\ ${ }^{\mathrm{h}}$ SPEC Inc., Boulder, Colorado \\ ${ }^{\mathrm{i}}$ University of Heidelberg, Heidelberg, Germany
}

(Manuscript received 2 December 2015, in final form 14 April 2016)

\begin{abstract}
Homogeneous freezing of supercooled droplets occurs in convective systems in low and midlatitudes. This droplet-freezing process leads to the formation of a large amount of small ice particles, so-called frozen droplets, that are transported to the upper parts of anvil outflows, where they can influence the cloud radiative properties. However, the detailed microphysics and, thus, the scattering properties of these small ice particles are highly uncertain. Here, the link between the microphysical and optical properties of frozen droplets is investigated in cloud chamber experiments, where the frozen droplets were formed, grown, and sublimated under controlled conditions. It was found that frozen droplets developed a high degree of small-scale complexity after their initial formation and subsequent growth. During sublimation, the small-scale complexity disappeared, releasing a smooth and near-spherical ice particle. Angular light scattering and depolarization measurements confirmed that these sublimating frozen droplets scattered light similar to spherical particles: that is, they had angular light-scattering properties similar to water droplets. The knowledge gained from this laboratory study was applied to two case studies of aircraft measurements in midlatitude and tropical convective systems. The in situ aircraft measurements confirmed that the microphysics of frozen droplets is dependent on the humidity conditions they are exposed to (growth or sublimation). The existence of optically spherical frozen droplets can be important for the radiative properties of detraining convective outflows.
\end{abstract}

\section{Introduction}

Convective systems are an important source of ice particles in the upper troposphere (e.g., Jensen et al. 1996; Gayet et al. 2012a; Frey et al. 2011) and the lowermost

Supplemental information related to this paper is available at the Journals Online website: http://dx.doi.org/10.1175/JAS-D-15-0365.s1.

Corresponding author address: Emma Järvinen, Institute of Meteorology and Climate Research, Karlsruhe Institute of Technology, P.O. Box 3640, 76021 Karlsruhe, Germany.

E-mail: emma.jaervinen@kit.edu stratosphere (de Reus et al. 2009). Ice particles found in the anvil outflows are usually formed in the lower and warmer part of the convective cell, and therefore their microphysical and optical properties differ from in situ formed ice particles (e.g., McFarquhar and Heymsfield 1996; Lawson et al. 2003; Connolly et al. 2005; Lawson et al. 2010; Frey et al. 2011). In midlatitude convective systems, supercooled liquid water droplets have been observed to survive down to a temperature around $-37^{\circ} \mathrm{C}$ (Rosenfeld and Woodley 2000), where homogeneous freezing of the supercooled droplets occurs. In vigorous convective systems, homogeneous freezing happens in a narrow time interval, producing a large amount of small 
ice crystals (Heymsfield and Sabin 1989; Phillips et al. 2007; Lawson et al. 2010). The ice particle concentrations at the top of convective systems can reach several tens per cubic centimeter, with the effective diameter of the ice particles staying below $50 \mu \mathrm{m}$ (Heymsfield et al. 2009; Lawson et al. 2010; Gayet et al. 2012a; Stith et al. 2014).

The high number of small ice particles at the top of convective outflows indicates that small $(<50 \mu \mathrm{m})$ ice crystals might be important for the shortwave radiative properties of these cloud types. Yet the exact microphysics and, therefore, the radiative forcing of small ice particles are not well understood. Several tropical (e.g., Stith et al. 2002; Lawson et al. 2003; Stith et al. 2004; Connolly et al. 2005; Heymsfield et al. 2005; May et al. 2008; Lawson et al. 2010; Frey et al. 2011) and a few midlatitude aircraft campaigns (e.g., Lawson et al. 2003; Gayet et al. 2012a; Stith et al. 2014) have been conducted to investigate the microphysical properties of ice crystals in anvil outflows. Gayet et al. (2012a) reported aggregated frozen droplets in a convective storm over Europe. Similarly, Stith et al. (2014) found that aggregated frozen droplets and single frozen droplets with median sizes of 20-25 $\mu \mathrm{m}$ are regular features in many midlatitude convective systems over the midwestern United States. In tropical convective systems, vaporgrown plates and aggregates of plates are typically detected (e.g., Connolly et al. 2005; Um and McFarquhar 2009; Frey et al. 2011). However, in fast updrafts homogeneous freezing can be observed (Heymsfield et al. 2005, 2009; Lawson et al. 2010).

Frozen droplets are quasi-spherical or quasi-spheroidal small particles that can be identified from measurements with cloud particle imagers (CPIs), which were used in the studies of Lawson et al. (2003), Gayet et al. (2012a), and Stith et al. (2014). The spatial resolutions of CPIs typically range from about 2 to $5 \mu \mathrm{m}$, depending on the probe model and aircraft speed: that is, too coarse to resolve the fine structure of small ice particles. What is detected as apparently a spherical ice particle may actually be a complex polycrystal, a droxtal, or a severely roughened ice particle (Z. Ulanowski et al. 2004, unpublished manuscript). However, particularly the fine structure or the particle complexity has an important role in determining the single-scattering properties of ice particles, in particular the forward-to-backward scattering ratio or asymmetry factor $g$, both of which are known to be decisive in radiative energy budget calculations (e.g., Li et al. 2004; Ulanowski et al. 2006; Yang et al. 2008; Baran 2012). This, consequently, influences the radiative forcing of the convective clouds. Yi et al. (2013) calculated a significant negative global average difference in shortwave radiative properties of $-1.46 \mathrm{~W} \mathrm{~m}^{2}$ between smooth and roughened ice crystals. Hence, accurate information on the detailed structure of frozen droplets is crucial to understand the radiative forcing of convective outflows, where homogeneous droplet freezing is observed.

Recently, a new instrument type has been developed to quantify the complexity of atmospheric ice crystals based on the analysis of their 2D diffraction patterns (Ulanowski et al. 2010; Schnaiter et al. 2016). In this context, crystal complexity comprises all types of distortions in a single crystal (e.g., surface roughness, hollowness, and air bubbles) that result in a similar spatial distribution of forward-scattered light. This structural complexity of a single ice crystal is referred to as smallscale complexity (Schnaiter et al. 2016). For example, a smooth ice sphere has a diffraction pattern similar to a water droplet, where concentric intensity maxima (rings) are observed in forward scattering. Small-scale complexity destroys this scattering pattern and induces randomization in the measured intensity distribution, and the degree of this randomization can be linked with the degree of the particle small-scale complexity (Schnaiter et al. 2016). Moreover, the 2D diffraction patterns can be used to discriminate aspherical ice particles from spherical particles (Vochezer et al. 2016). Normally, the latter method is deployed to determine ice fractions in mixedphase clouds, but in this study we used it to detect optically spherical ice particles in simulated and in real ice clouds of convective origin.

In this paper, two definitions are used to describe the microphysical nature of the frozen droplets: "quasi spherical" and "optically spherical." Quasi spherical is used as a general term for all frozen droplets that have retained their apparent spherical shape in the freezing process and are identified as spherical particles in the CPI images. Similarly, Nousiainen and McFarquhar (2004) defined a quasi-spherical ice particle as a particle whose projected area resembles a circle. The term quasi spherical is frequently used to describe small ice particles (e.g., Gayet et al. 1996; Korolev and Isaac 2003; McFarquhar et al. 2007), yet the actual shape of these particles can be nonspherical if surface roughness or other smallerscale structural complexity is present. For calculating the scattering properties, the term quasi spherical can be misleading, as it can be related to calculating the ice particle radiative properties using the Lorenz-Mie theory (Yang et al. 2003). To better illustrate the optical effect of these ice particles, we introduce the term optically spherical to describe frozen droplets that do not show crystal complexity and behave optically like a sphere according to our measurement methods.

The droplet freezing process was simulated in the cloud simulation chamber Aerosol Interactions and Dynamics in the Atmosphere (AIDA; Möhler et al. 2003), where 
frozen droplets were grown and sublimated under controlled conditions. During the growth and sublimation cycles, the size, shape, complexity and angular light-scattering properties of the frozen droplets were investigated to understand the link between environmental, microphysical, and optical properties. The paper is organized as follows. The new instrument type and the analysis methods for determining particle small-scale complexity and sphericity are briefly discussed in section $2 \mathrm{a}$. The cloud chamber and the experiment method are described in section $2 b$, and the results from the chamber experiments are discussed in section 3. The knowledge gained from the laboratory study was applied to two case studies of aircraft measurements in mid- and low-latitude convective systems. The results from these two case studies are presented and discussed in sections 4 and 5 , and the atmospheric relevance of quasi-spherical ice particles is the topic of section 6 .

\section{Methods}

\section{a. Detecting optically spherical particles}

A set of instruments measuring different optical parameters was used to determine the sphericity of laboratoryproduced ice particles. The airborne Small Ice Detector, mark 3, [SID-3; see details in Ulanowski et al. (2012), Ulanowski et al. (2014), and Vochezer et al. (2016)] and its laboratory version, the Particle Phase Discriminator, mark 2, Karlsruhe edition [PPD-2K; see details in Kaye et al. (2008) and Vochezer et al. (2016)] record high-resolution scattering patterns of particles that have passed a 532-nm laser beam that can be used to study the particle morphology in size ranges of 3-50 (SID-3) and 7-70 $\mu \mathrm{m}$ (PPD$2 \mathrm{~K})$. In addition, the crystal small-scale complexity can be derived from these measurements (Schnaiter et al. 2016). A detailed description of the technical details and the data analysis methods of these two instruments can be found in Vochezer et al. (2016) and Schnaiter et al. (2016). Here we only briefly describe how the scattering patterns are used to quantify particle sphericity and aspherical fraction.

The SID-3 and PPD-2K record forward-scattered light from a single cloud particle in an annulus region between $7^{\circ}$ and $26^{\circ}$ using an intensified charged coupled device camera (ICCD). This pattern can be averaged over the polar angle to get a median forward-scattering azimuthal intensity profile for a single particle. In the case of a spherical scatterer, a scattering pattern with concentric rings can be described with the Lorenz-Mie theory. Taking the average over the polar angles of a spherical particle, therefore, leads to a flat azimuthal intensity profile, whereas in the case of an aspherical scatterer, the azimuthal intensity profile is nonuniform. Hence, the variance of the intensity along the azimuthal angle $v_{\text {az }}$ can be used to quantify the degree of particle sphericity. The fraction of aspherical particles is determined using a calibrated threshold value of $v_{\mathrm{az}}^{\mathrm{thr}}$ of $1 \times 10^{-5}$, with particles having a $v_{\mathrm{az}}<\boldsymbol{v}_{\mathrm{az}}^{\mathrm{thr}}$ classified as spherical. The typical $v_{\mathrm{az}}$ value for water droplets is between $1 \times 10^{-6}$ and $1 \times 10^{-5}$, depending on the droplet size, and the typical $v_{\mathrm{az}}$ for a columnar ice particle in chamber experiments is around $1 \times 10^{-1}$. Irregular ice particles have $v_{\mathrm{az}}$ values between those of droplets and hexagonal ice particles.

In addition to SID-3 and PPD-2K, two airborne cloud particle spectrometers, the Novel Ice Experiment-Cloud and Aerosol Particle Spectrometer (NIXE-CAPS) and the Cloud Aerosol Spectrometer-Depolarization Option (CAS-DPOL) were deployed in the chamber experiments. NIXE-CAPS (Meyer 2012; Luebke et al. 2015) is a combination of a cloud imaging probe and a cloud aerosol spectrometer. The design of the NIXE-CAPS instrument is similar to the cloud, aerosol, and precipitation spectrometer (CAPS; Baumgardner et al. 2001); however, one modification is that the NIXE-CAPS has a detector for the cross-polarized component of the backward-scattered light (see Meyer 2012; Baumgardner et al. 2014). This instrument supports the measurement of single-particle polarization signals that can be used to determine if a cloud particle is aspherical, as aspherical particles do significantly alter the polarization state of the incident light. Each particle's polarization signal is compared to a size-dependent "asphericity threshold" that was developed based on measurements of spherical liquid water droplets (Meyer 2012). The smallest particles that can be detected with the NIXE-CAPS instrument have diameters of about $0.6 \mu \mathrm{m}$; however, in this study the aspherical fractions was determined only for particles larger than $8 \mu \mathrm{m}$ to be comparable to the PPD-2K measurements.

Similar to the NIXE-CAPS, the aspherical fraction from the CAS-DPOL (Voigt et al. 2016) is determined by the ratio of perpendicularly polarized light to the forwardscattering light intensity. Again, a size-dependent threshold was determined from the measurements of spherical liquid particles, and all particles with a polarization ratio larger than the $1 \sigma$ range of threshold values were categorized as aspherical. The method gives a size-dependent aspherical fraction similar to the PPD-2K as well as the bulk aspherical fraction. The bulk aspherical fraction was derived from the number of aspherical particles to the number of total particles measured between 8 and $50 \mu \mathrm{m}$ within a 10 -s time interval.

Besides particle probes, two polar nephelometers were used to measure the angular light scattering of the frozen 
droplets. The airborne polar nephelometer (PN; Gayet et al. 1997; Crépel et al. 1997) measures the polar scattering function of a particle ensemble in the angular range between $3.5^{\circ}$ and $169^{\circ}$. In this paper, the asymmetry parameter $g$ is assessed based on the angular scattering measurements documented between $15^{\circ}$ and $155^{\circ}$. We followed the methodology proposed by Gerber et al. (2000), assuming that the fraction of energy scattered into angles smaller than $15^{\circ}$ is constant and equal to 0.56 , regardless of the cloud composition. The absolute error on the asymmetry parameter is expected to range approximately between 0.04 (Gerber et al. 2000; Garrett et al. 2001; Gayet et al. 2002) and 0.05 (for clouds dominated by large ice crystals).

The airborne Particle Habit Imaging and Polar Scattering probe on the German High-Altitude and LongRange Research Aircraft (PHIPS-HALO; Abdelmonem et al. 2016) was used together with PN to measure the angular light-scattering function of single particles in an angular range of $18^{\circ}$ to $170^{\circ}$. The basic measurement concept of PHIPS-HALO is the simultaneous imaging of single ice crystals and the measurement of their angular scattering function. The imaging part of the instrument consists of two identical camera-telescope assemblies and a pulsed incoherent illumination laser. The use of incoherent laser light enables the production of diffraction- and chromatic-aberration-free bright-field microscopic images with an optical resolution of about $2.5 \mu \mathrm{m}$. The polar nephelometer part of PHIPS-HALO measures the light scattered from particles as they pass through the horizontally aligned scattering laser beam with a wavelength of $532 \mathrm{~nm}$. The light scattered from a particle is collected with 20 parabolic mirrors at equidistant angular separations of $8^{\circ}$ (from $18^{\circ}$ to $170^{\circ}$ ). Their diameter is $10 \mathrm{~mm}$ so that the angular range that each mirror covers is $\pm 3.5^{\circ}$. The light gathered by the mirrors is focused into optical fibers and transported to a multianode photomultiplier array for analysis.

The ensemble cloud-scattering properties were probed with an in situ scattering and depolarization instrument Streulichtintensitätsmessungen zum Optischen Nachweis von Eispartikeln (SIMONE) ${ }^{1}$ (Schnaiter et al. 2012; Järvinen et al. 2016). SIMONE measures the intensity of the scattered light from the center of the chamber at nearforward- $\left(2^{\circ}\right)$ and at near-backward-scattering angles $\left(178^{\circ}\right)$. The backward scattered light is decomposed into its polarization components to determine the linear

\footnotetext{
${ }^{1}$ The German project title Streulichtintensitätsmessungen zum Optischen Nachweis von Eispartikeln can be translated as Scattering Intensity Measurements for the Optical Detection of Ice Particles.
}

depolarization ratio $\delta_{l}$. This $\delta_{l}$ can be considered as a direct and accurate measure of the particle sphericity; spherical particles do not change the linear polarization state of the incident light in the scattering process, whereas aspherical particles induce a nonzero depolarization ratio, with the magnitude depending on the shape, size, and refractive index of the particle.

\section{b. Simulating convective cloud systems in AIDA}

The expansion cooling of an air parcel in a convective system was simulated in the cloud chamber AIDA (Möhler et al. 2003) located at the Karlsruhe Institute of Technology. The AIDA chamber consists of a large $84-\mathrm{m}^{3}$ aluminum vessel that is enclosed inside thermal housing. The chamber can be cooled down to $183 \mathrm{~K}$, which makes the AIDA chamber suitable for simulating ice microphysics in pure ice clouds (Schnaiter et al. 2012, 2016), in persistent mixed-phase clouds (Vochezer et al. 2016), and in convective systems (this study). To form liquid and ice clouds, supersaturated conditions inside the chamber are reached by expansion cooling; the chamber is evacuated from atmospheric pressure down to $600-800 \mathrm{hPa}$, depending on the pumping speed and the required amount of cooling. The typical cooling rates that can be achieved at the beginning of the expansion range from $-1 \mathrm{~K} \mathrm{~min}^{-1}$ to a maximum of $-2.5 \mathrm{~K} \mathrm{~min}^{-1}$, which roughly corresponds to updraft speeds from 2 to $7 \mathrm{~m} \mathrm{~s}^{-1}$, values typical for midlatitude convection over the United States (Giangrande et al. 2013).

To study the ice particle microphysics in convective systems, a specific experimental procedure was developed containing three phases: 1) pure liquid cloud with supercooled droplets, 2) freezing of the droplets and their initial growth at supersaturated conditions, and, finally, 3) the sublimation of the frozen droplets at subsaturated conditions. The experiments were started with a clean chamber precooled to $243 \mathrm{~K}$. Near-ice saturated conditions inside the chamber were achieved by coating the chamber walls with an ice layer [see a more detailed description of the chamber preparation in Wagner et al. (2009)].

In the first phase of the experiment, a cloud of supercooled droplets was generated using sulfuric acid (SA) solution droplets or dust particles originating from Argentina as seed aerosol. The SA solution droplets were generated using a generator specifically designed for AIDA (Möhler et al. 2003). The soil dust aerosol was added to the chamber by using a rotating brush generator (RBG 1000, Palas) to disperse the particles and a cyclone impactor to remove particles larger than about $3 \mu \mathrm{m}$ in diameter (e.g., Möhler et al. 2008). The concentration inside the chamber was constantly monitored with a condensation particle counter (CPC3010, TSI). 
Different seed aerosol concentrations of about 10, 100, and $1000 \mathrm{~cm}^{-3}$ were used to produce liquid particles of different diameters. Here, we present data from three experiments: two simulating homogeneous freezing in SA solution droplets with different initial concentrations (experiments 15 and 17) and one simulating heterogeneous nucleation on soil dust (experiment 24). The numbering of the experiment corresponds to the sequence of the expansion in the AIDA campaign Rough Ice 3 (RICE03). The formation of the droplets was initiated by an expansion of the chamber gas, which led to a cooling of the chamber volume and an increase of the relative humidity (RH). The RH inside the chamber was measured with a combination of a fast chilledmirror frost-point hygrometer (MBW, model 373) that measures the total (gas and condensed phase) water vapor concentration in the chamber, and with a tunable diode laser (TDL) spectrometer (Fahey et al. 2014) that measures the water vapor concentration. After water saturated conditions were reached, a cloud of supercooled droplets formed. In the experiments, almost all the seed aerosol particles were activated to form cloud droplets so that the initial droplet concentration was determined by the seed aerosol concentration.

The cooling of the chamber volume was continued until a mixed-phase cloud consisting of frozen and supercooled droplets was formed. In the mixed-phase cloud, the freshly formed frozen droplets grew through the Bergeron-Findeisen process, and, since the expansion cooling was continued, also because of deposition growth in an ice supersaturated environment. The duration of the mixed-phase cloud was dependent on the pumping speed and the initial aerosol concentration. Three different pumping speeds were used: $60 \%$, $80 \%$, and $90 \%$ of the maximum speeds, corresponding to cooling rates of $-1.5,-2$, and $-2.5 \mathrm{~K} \mathrm{~min}^{-1}$, respectively. After full glaciation of the cloud, the frozen droplets continued the growth in supersaturated conditions (phase 2 of the experiment). During this phase, the microphysical and optical properties of the frozen droplets were observed with the in situ instruments: SID-3, PPD-2K, NIXE-CAPS, CASDPOL, PHIPS-HALO, and PN. The ensemble scattering and depolarization ratio was measured with SIMONE.

The frozen droplets were grown to maximum sizes between 40 and $50 \mu \mathrm{m}$. Then the expansion period was stopped, and a small compression was introduced to create subsaturated conditions. The sublimation of the frozen droplets denoted the third phase of the experiment. The same set of instruments was used to monitor the microphysical and optical properties of the sublimating frozen droplets.

\section{Results from cloud chamber experiments}

In situ measurements have provided evidence that, in midlatitude convective systems, supercooled liquid water can exist to temperatures around $237 \mathrm{~K}$, where homogeneous freezing quickly converts the droplets into ice particles (Rosenfeld and Woodley 2000). AIDA cloud simulation experiments on the homogeneous freezing of supercooled droplets in convective systems are described in section 3a. In these experiments, the ice particles were formed through liquid phase (droplet freezing) and, therefore, in the following sections these laboratory-produced ice particles are called "frozen droplets," independent of their actual shape. The microphysical properties of liquid-origin ice particles may differ greatly from those of ice particles formed and grown through the vapor phase. Therefore, an experiment with soil dust as seed aerosol was performed for comparison (described in section $3 \mathrm{~b}$ ), where the ice formed through the deposition nucleation mode and grew by vapor diffusion. The differences in the ice microphysical and optical properties between frozen droplets with liquid origin and deposition nucleationformed ice crystals at the same temperature regime are the subject of this section.

\section{a. Ice particle formation through the liquid phase}

Figure 1 shows a droplet freezing experiment conducted with an initial number concentration of $12-\mathrm{cm}^{-3}$ SA solution droplets. The expansion was started at experiment time $0 \mathrm{~s}$, as indicated by the start of the pressure decrease in Fig. 1a. The cooling rate at the beginning of the expansion was $-2.5 \mathrm{~K} \mathrm{~min}^{-1}$, but in the course of the expansion the heat flux from the chamber walls reduced the cooling rate. At experiment time $83 \mathrm{~s}$, water saturation was reached (dashed blue line in Fig. 1b), and a cloud of supercooled liquid droplets was formed, indicated by the rapid increase in the forward-scattering intensity (Fig. 1c). Moreover, a zero depolarization ratio was measured indicating the presence of spherical particles in this period. The cloud particles were detected by the PPD-2K instrument after experiment time $100 \mathrm{~s}$, when they have grown to diameters above $7 \mu \mathrm{m}$ (Figs. 1d,e). In this first phase of the experiment, the $2 \mathrm{D}$ diffraction patterns of supercooled droplets recorded by the PPD-2K showed a concentric ring pattern [(i) in Fig. 2] with $v_{\mathrm{az}}$ below the threshold value of $1 \times 10^{-5}$ (Fig. 1e).

The cooling was continued until the homogeneous freezing threshold around $237 \mathrm{~K}$ was reached at the experiment time $132 \mathrm{~s}$. This led to a rapid glaciation of the cloud through homogeneous freezing of the supercooled droplets. Just before freezing, the liquid droplets had reached a median diameter of $14 \mu \mathrm{m}$ 

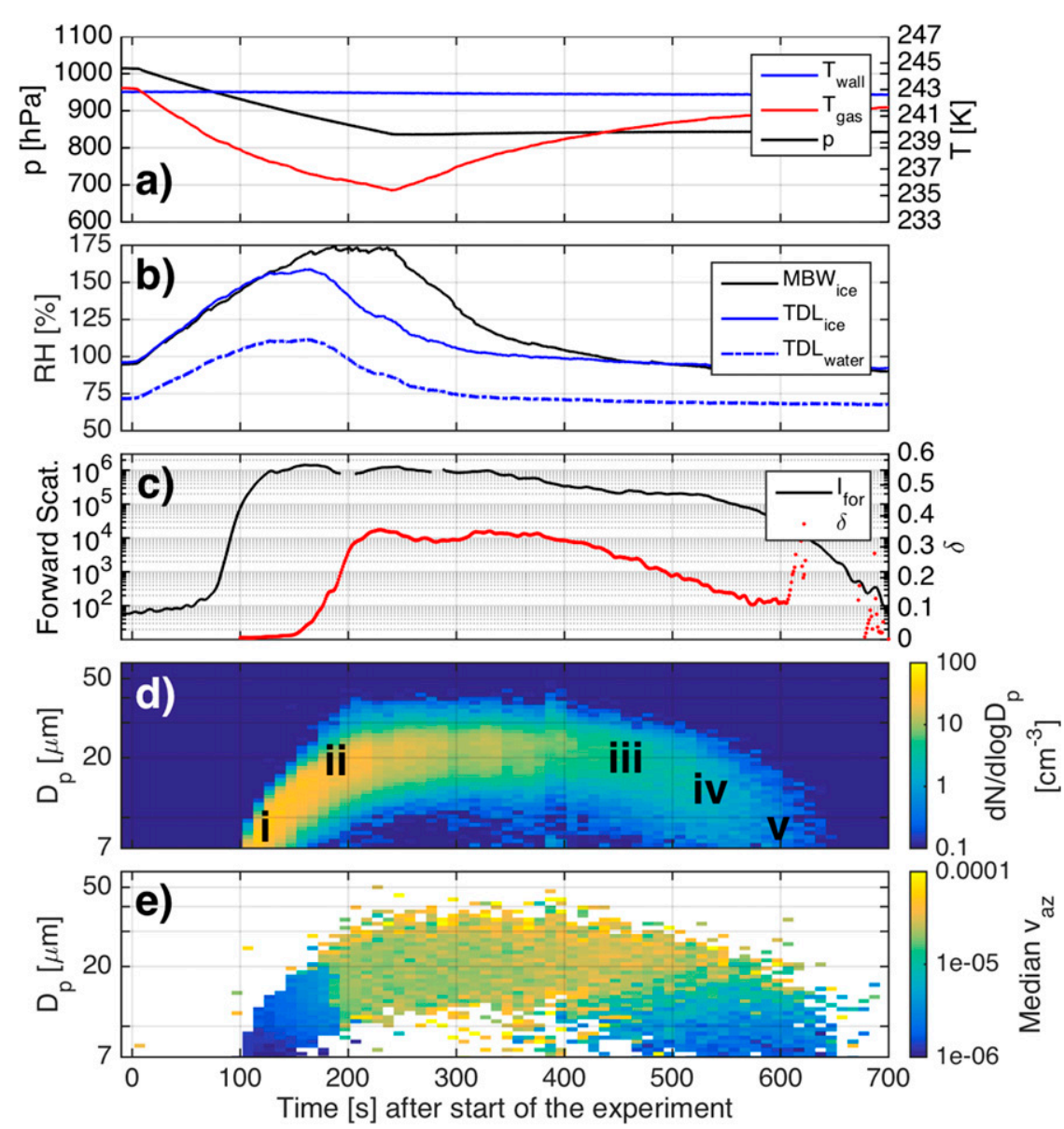

FIG. 1. A droplet freezing experiment (experiment 17) initiated with $12 \mathrm{~cm}^{3}$ of sulfuric acid aerosol and a pumping speed of $90 \%$ that led to an initial cooling rate of $-2.5 \mathrm{~K} \mathrm{~min}^{-1}$. (a) The pressure of the chamber (black line) as well as the chamber and wall temperatures (red and blue lines, respectively). (b) The total water measured with MBW (black line) and the interstitial water with respect to ice (blue solid line) and water (blue dashed line) measured with TDL. (c) The forward-scattering intensity (black line) and the depolarization ratio (red dots) were measured for cloud particles in the middle of the chamber. (d) The PPD-2K size distribution. (e) The size-segregated median variance of the $2 \mathrm{D}$ scattering patterns. The expansion of the chamber volume was started at experiment time $0 \mathrm{~s}$.

(Fig. 3). The glaciation of the cloud led to an increase of the ice water content (IWC), as indicated by the difference between the total water (MBW; black line in Fig. 1b) and the interstitial water (TDL; solid blue line in Fig. 1b). At the same time, the depolarization ratio (Fig. 1c) started to depart from zero and reached a maximum of $\sim 0.3$ at $200 \mathrm{~s}$ after the droplets were fully depleted. The optical size of the frozen droplets did not significantly differ from the droplet size of the initial liquid, and therefore the glaciation is not visible in the PPD-2K size distribution (Fig. 1d). Yet the variance analysis clearly showed an increase in $v_{\mathrm{az}}$ during the mixed-phase conditions, and a sharp transition to $v_{\mathrm{az}}$ above the threshold value of $1 \times 10^{-5}$ was observed after full glaciation.
The PPD-2K scattering patterns of ice particles during the growth in mixed-phase conditions and, later, through vapor deposition, were dominated by speckles [(ii) in Fig. 2], indicating a significant degree of small-scale complexity. We determined the small-scale complexity of the particles from the SID-3 scattering patterns using the method described in Schnaiter et al. (2016). This method relies on the gray-level co-occurrence matrix (GLCM) method described in Lu et al. (2006). The speckle-pattern features can be extracted from the GLCM by calculating features, like the energy feature. It was found in Lu et al. (2006) and Schnaiter et al. (2016) that the exponential fit coefficient to the energy feature, the so-called $k$ value $k_{e}$, best described the physical complexity, and therefore we use $k_{e}$ as the 


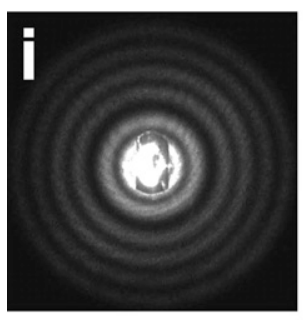

$V_{a z}=1.0 \mathrm{E}-06$

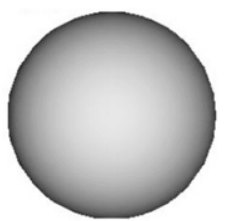

$\sigma=0.0$

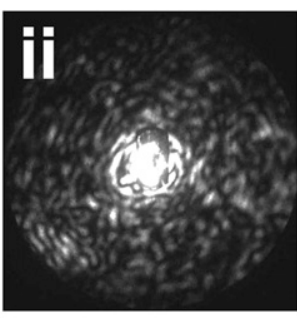

3.1E-05

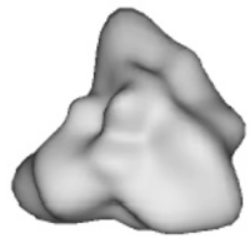

0.3

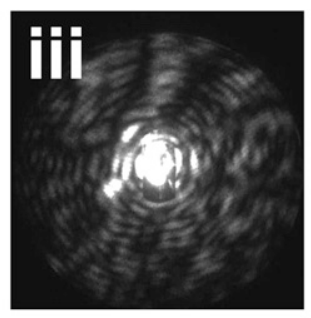

3.0E-05

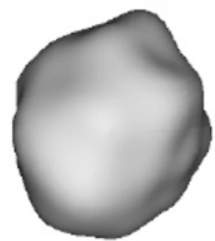

0.1

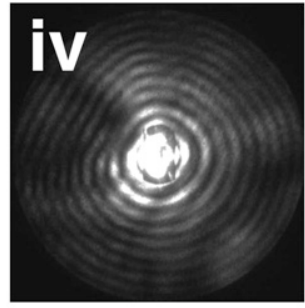

2.0E-05

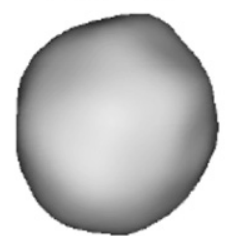

0.05

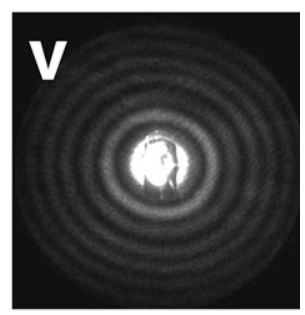

3.2E-06

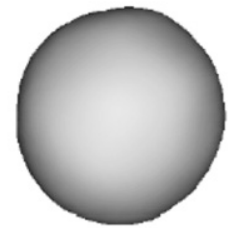

0.02

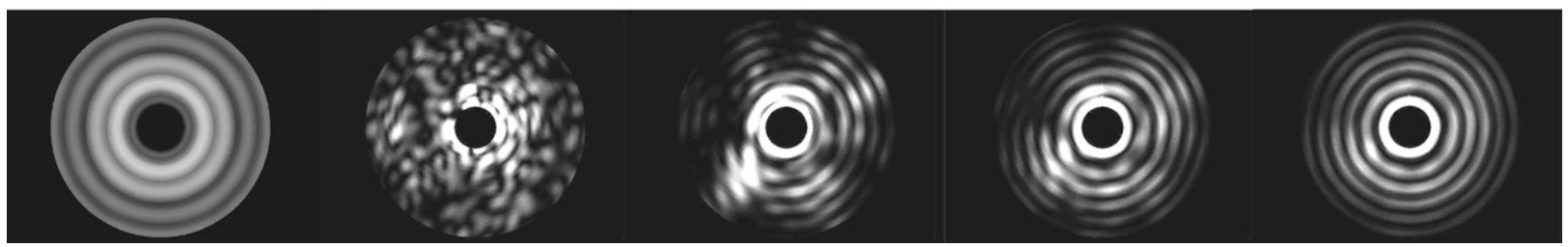

FIG. 2. Simulation of the deformation of sphere's surface with a Gaussian random sphere model. (middle) The surface of a sphere was altered with a relative deformation between 0 and 0.3 . (bottom) The resulting $2 \mathrm{D}$ scattering patterns. (top) Particles i-v were measured with the PPD-2K during experiment 17 (Fig. 1). The $v_{\mathrm{az}}$ values describe the degree of asphericity in the real ice particles according to the measurement technique. Changing the surface of the model spheres explained the observed diffraction patterns.

complexity parameter in the remainder of this study. Values of $k_{e}$ can be between 4 and 6 so that increasing physical complexity results in a larger $k_{e}$ value. In the case of columnar particles, Schnaiter et al. (2016) determined a threshold value of 4.6 to discriminate between complex $\left(k_{e} \geq 4.6\right)$ and pristine columns $\left(k_{e}<4.6\right)$.

In our case, we measured a $k_{e}$ value of 6.5 for frozen droplets formed from liquid phase (Fig. 4). This value was significantly larger than what was measured for vaporgrown ice crystal at cirrus temperatures (Schnaiter et al. 2016). Schnaiter et al. (2016) showed that the small-scale complexity is driven by the available water vapor mixing ratio $\zeta_{v}^{\text {acw }}$ : that is, the number of water molecules that are free to condense to the ice phase. In the chamber experiments with vapor-grown ice crystals at cirrus temperatures, the $\zeta_{v}^{\text {acw }}$ varied between 0 and 20 ppmv (Schnaiter et al. 2016), whereas in this experiment we derived a $\zeta_{v}^{\mathrm{acw}}$ value of $80 \mathrm{ppmv}$. This enhancement is likely promoted by the Bergeron-Findeisen process, the warmer temperature, and the initial growth at nearwater saturation. It is possible that the small-scale complexity of liquid-origin ice particles could be severely enhanced compared to in situ grown ice crystals. Large-scale complexity (e.g., riming) is frequently found in mixed-phase cloud (e.g., Ono 1969), but as a result of instrument limitations, small-scale complexity could not be studied. Therefore, field measurements in mixed-phase regions with SID-type instruments would be needed to validate our laboratory findings.

The growth of the frozen droplets was stopped after a median diameter of $22 \mu \mathrm{m}$ was reached (Fig. 3). In the third phase of the experiment, the frozen droplets were forced to sublimate under ice-subsaturated conditions. The sublimation was seen in the PPD-2K diffraction patterns, as ringlike patterns started to emerge, and these patterns became more concentric toward the end of the sublimation. The emerging of the rings can be linked with the decrease in the crystal complexity (Fig. 4). This is also seen in $v_{\text {az }}$ (Fig. 1e); $v_{\text {az }}$ slowly decreased to values below the threshold value, and at the end of the sublimation period, $v_{\mathrm{az}}$ of the sublimating frozen droplets was almost equivalent to that of liquid droplets [cf. $v_{\mathrm{az}}$ of the liquid droplet (i) and sublimating frozen droplet (v) in Fig. 2]. However, these optically spherical particles cannot be liquid droplets, as the temperature during sublimation period of the fully glaciated cloud stayed well below $-30^{\circ} \mathrm{C}$. Furthermore, the depolarization ratio decreased from 0.3 measured for complex frozen droplets to 0.1 measured for sublimating frozen droplets, providing further evidence of the changing particle shape. At the end of the sublimation, the 

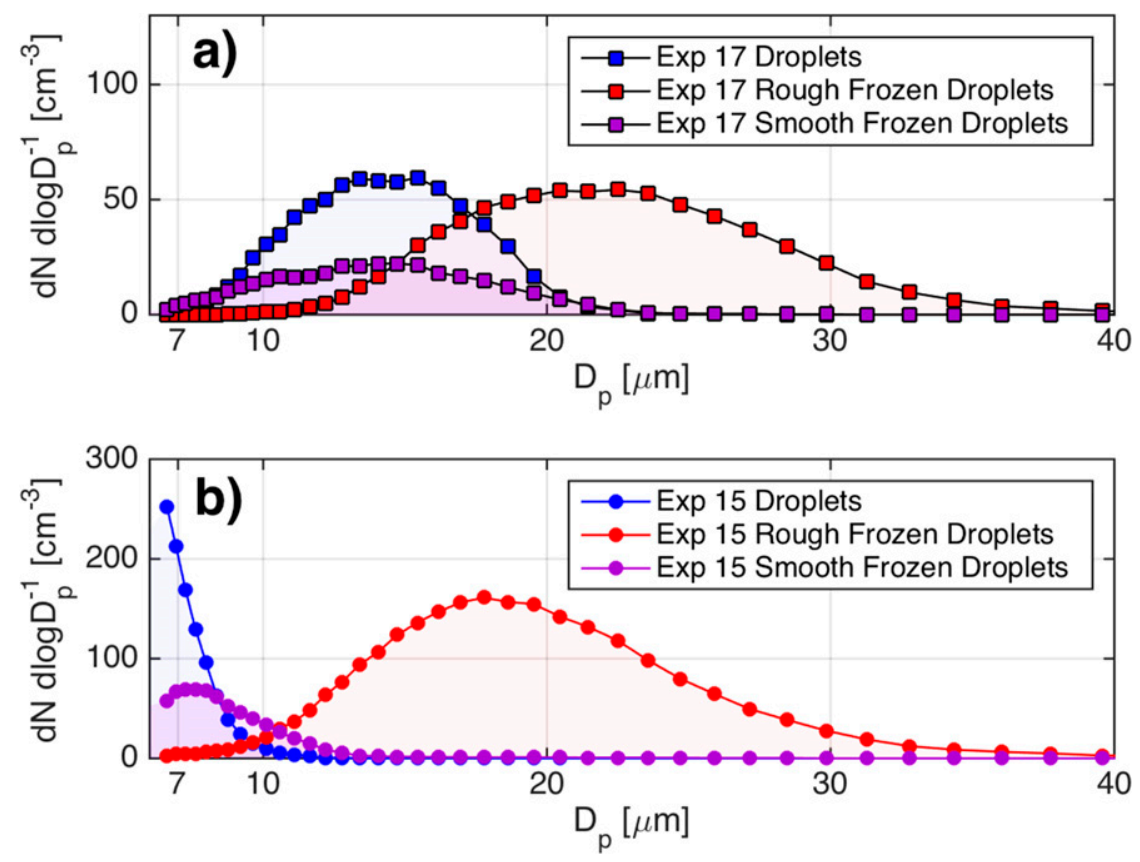

FIG. 3. Averaged size distributions of supercooled droplets before freezing, rough frozen droplets when their size is at maximum, and smooth sublimating frozen droplets. (a) Experiment 17 was started with an aerosol concentration of $12 \mathrm{~cm}^{3}$ and (b) experiment 15 with $989 \mathrm{~cm}^{3}$. The size of the sublimated and optically spherical frozen droplets is governed by the size of the supercooled droplets before freezing.

frozen droplets were observed to have diffraction patterns similar to spherical particles [(v) in Fig. 2]; that is, the particles were optically spherical, and the particle size distribution established was close to that of the supercooled droplets at the beginning (Fig. 3).

The difference between optically spherical and quasispherical ice particles is well depicted in Fig. 5. It shows the PHIPS-HALO images of frozen droplets during the experiment in a chronological order. At the beginning, the ice particles seem almost perfectly spherical, although, based on the PPD-2K variance analysis and the SID-3 complexity analysis, we know that these particles were highly distorted. The distortion lies in the microstructures of these particles and therefore cannot be seen from the PHIPS-HALO images with restricted resolution. Only after a certain growth does the nonspherical nature of these particles emerge. During sublimation, the ice particles rather quickly lose the clear aspherical features and become again quasi spherical. Now, both the variance analysis and the complexity analysis agree that the quasi-spherical particles also are optically spherical. Therefore, although the first and last PHIPS-HALO images in Fig. 5 look almost identical, their lightscattering properties are very different, which highlights the need for sophisticated measurement techniques for the investigations of the microphysical nature of small ice particles.
The experiment procedure was repeated with different concentrations of SA solution droplets as seed aerosol. The seed aerosol number controls the size distribution of the supercooled droplets so that, the higher the seed aerosol concentration is, the more droplets are formed, and their size remains smaller (see blue curves in Fig. 3). With an initial concentration of $989 \mathrm{~cm}^{-3}$, the median diameter of the supercooled droplets stayed below $7 \mu \mathrm{m}$ before freezing. Since the droplets were smaller, the ice particles also remained smaller, with median diameter of $18 \mu \mathrm{m}$ (Fig. 3). During sublimation, the size distribution of the smooth frozen droplet cores was again similar to the initial droplet size distribution. Therefore, it can be concluded that the liquid droplets kept their spherical form in the freezing process, but the spherical shape was quickly distorted under the rapid depositional growth under near-water-saturated conditions. Under sublimation, it is possible to regain the spherical core, and the size of this core is comparable to the original droplet size.

\section{1) FORMATION OF A FROST LAYER DURING THE GROWTH OF FROZEN DROPLETS}

A variation of structural or morphological deformities in a single ice crystal can cause speckles to appear in the PPD-2K diffraction patterns. However, in the case of laboratory-produced frozen droplets, the speckles in the 


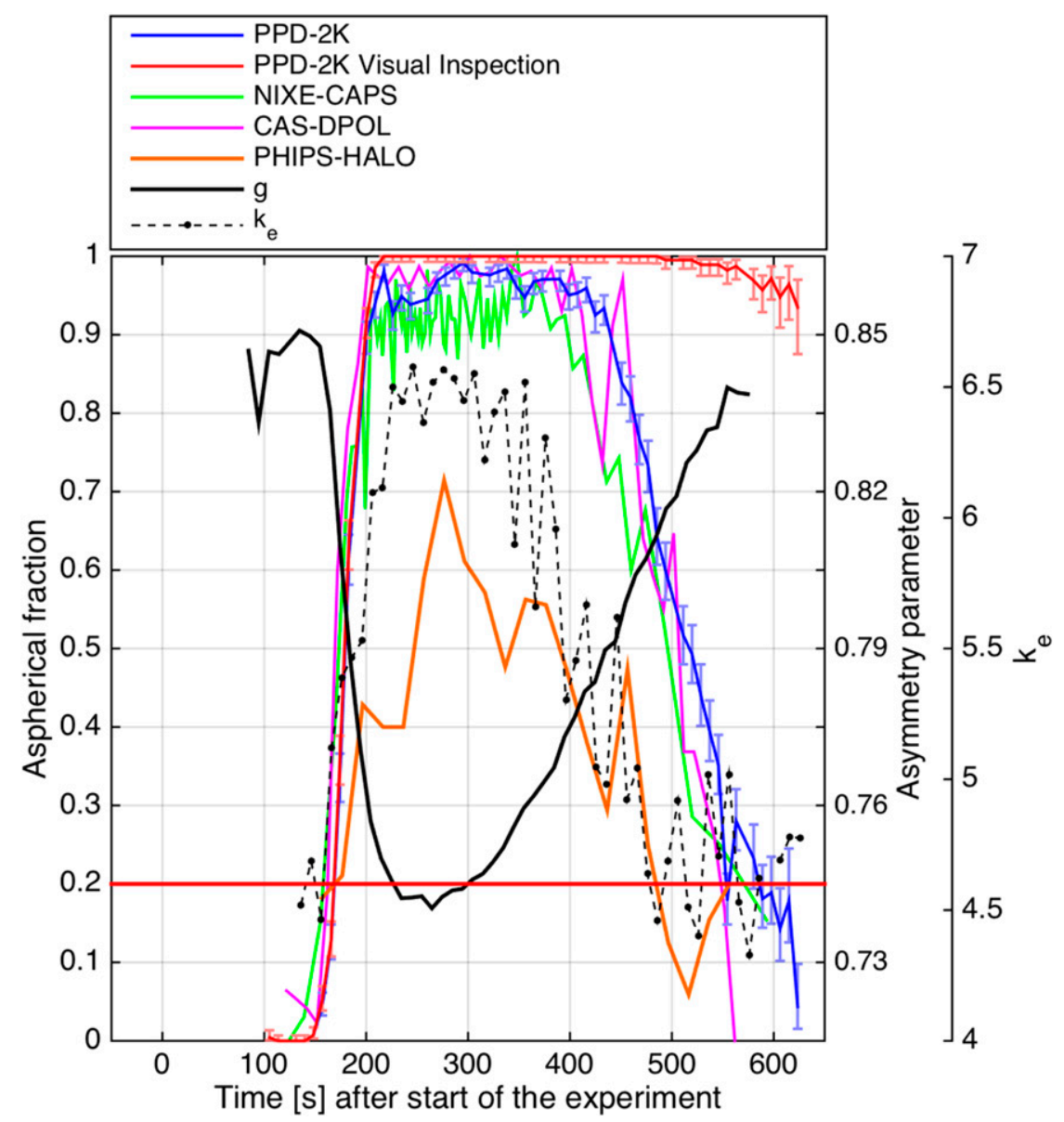

FIG. 4. Aspherical fractions during experiment 17 (Fig. 1) from PPD-2K (blue line) using an automated routine or applying a manual cross-check (red line) from NIXE-CAPS (green line) and from CAS-DPOL (magenta line). Also shown are the asymmetry parameter $g$ (black solid line) determined from PN measurements and the complexity parameter $k_{e}$ (black dashed line) determined from SID-3 measurements.

diffraction patterns were most likely caused by the development of surface roughness over a spherical core in the initial growth. As the amount of condensable water vapor was high during the initial growth, the deposition of the water molecules probably took place all over on the surface, instead of prismatic edges leading a frost layer to develop. Since the growth took place all over the surface, the frozen droplets were observed to be quasi spherical in the PHIPS-HALO images (Fig. 5). Only in the later growth phase do the ice particles seem to deviate more clearly from a spherical shape. Similar growth behavior was observed in the study of Korolev et al. (2004), where large $(>100 \mu \mathrm{m})$ droplets were observed to grow quasi spherical in a diffusion chamber. The observations could also explain field observations, where frozen droplets had maintained their quasi-spherical form in their formation, growth, and transportation to anvil regions (e.g., Stith et al. 2014).
The scale of the surface roughness that can be observed with the SID-3 method is from $100 \mathrm{~nm}$ to about $1 \mu \mathrm{m}$ (Lu et al. 2006; Schnaiter et al. 2016). Figure 6 shows an illustration of how a physical frost layer with the roughness scale could look in the case of a complex frozen droplet. In subsaturated conditions, the sharp edges of the frost layer are sublimated first, since they have a higher saturation vapor pressure. Eventually, the frost layer can be completely obliterated so that a smooth spherical core remains, as seen in the PHIPS-HALO (Fig. 5) and PPD-2K images (Fig. 2).

We investigated the effect of surface roughness on the light-scattering properties in the angular range of the PPD-2K instrument by using a Gaussian random sphere geometry [see details in Schnaiter et al. (2016)]. Similarly, Nousiainen and McFarquhar (2004) used the same model to study quasi-spherical ice particles. The model particles and the corresponding diffraction patterns at 


\section{$\longmapsto 100 \mu \mathrm{m}$}

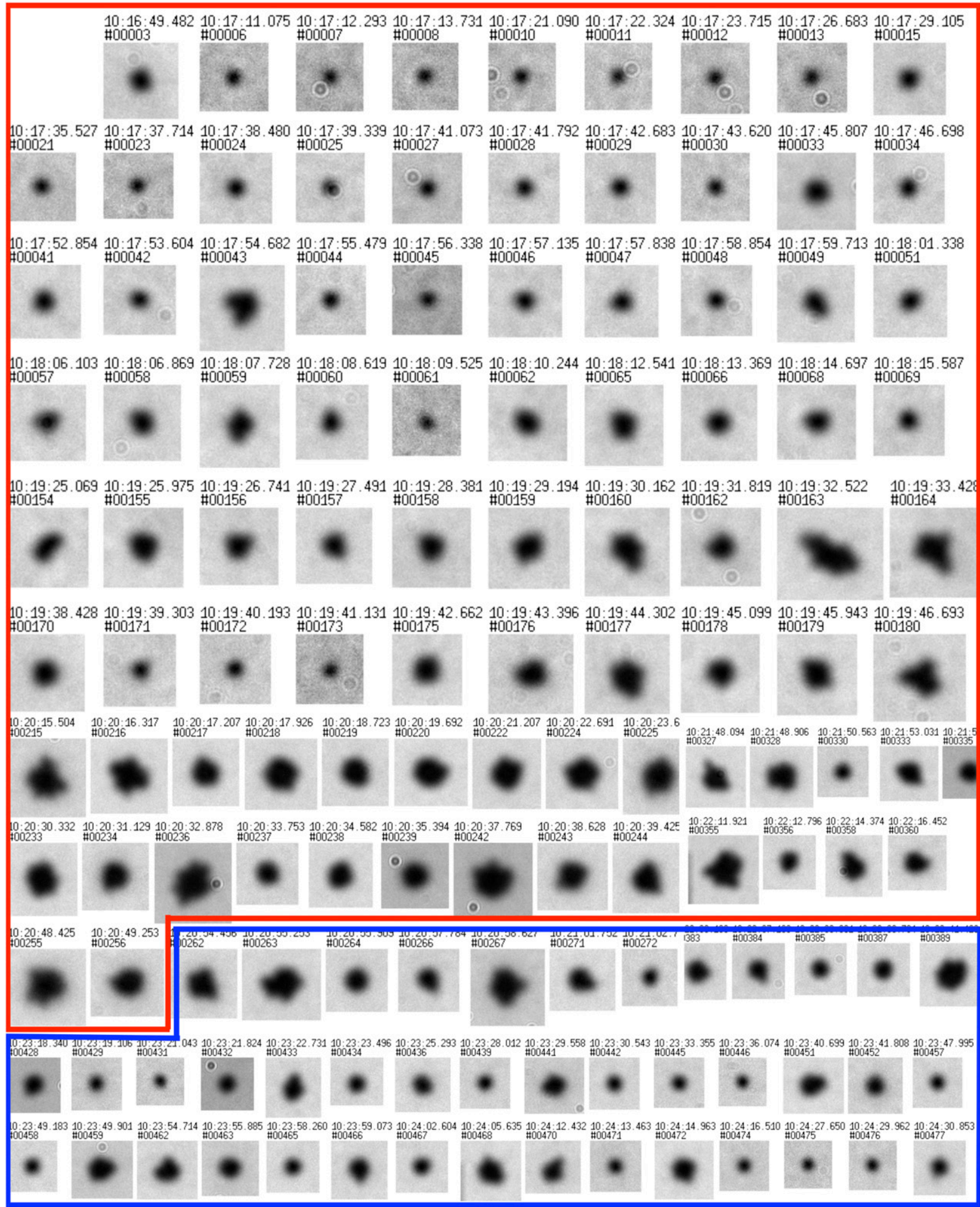

FIG. 5. A collection of PHIPS-HALO ice particle images from growth phase (highlighted with red box) and from sublimation phase (highlighted with blue box) of experiment 17. The images are shown in chronological order. 


\section{Supercooled Liquid Droplet}

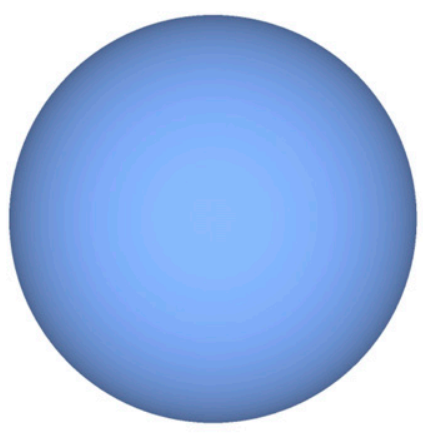

Complex Frozen

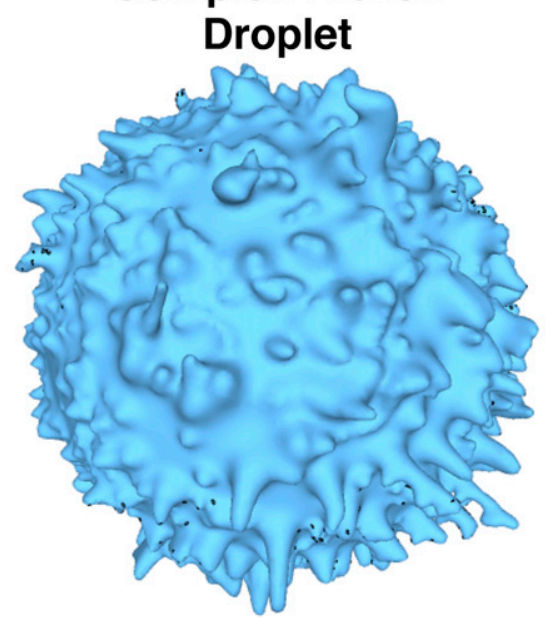

Smooth Frozen Droplet

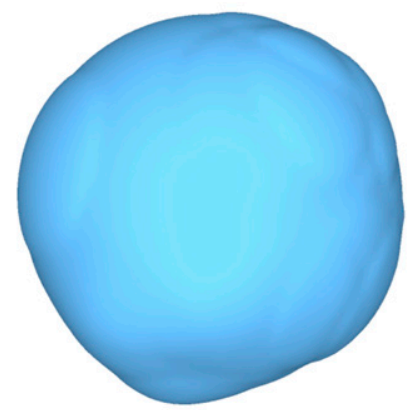

FIG. 6. Proposed microphysical model for the frozen droplets. Supercooled liquid droplets freeze and develop a frost layer on the surface of the particles in the initial growth. In the sublimation, the fine structure of the frost layer is sublimated first, and after a certain time a smooth optically spherical core can be detected.

the angular range of the PPD-2K instrument are shown in Fig. 2. The modulation of the model sphere's surface results in similar diffraction patterns that were measured for the complex frozen droplets. Furthermore, by decreasing the degree of the distortion, the underlying ringlike diffraction patterns of a sphere emerge, similar to what was seen in the measurements. However, it should be kept in mind that surface modulation in the Gaussian random sphere model does not necessarily accurately describe the physical frost layer.

\section{2) COMPARISON OF ASPHERICAL FRACTIONS}

The values of $v_{\mathrm{az}}$ measured with PPD-2K can be converted into an aspherical fraction by applying $v_{\text {az }}$. Figure 4 shows the aspherical fraction as a function of experiment elapse time determined from the PPD-2K using the variance analysis and, as a comparison, from NIXE-CAPS and from CAS-DPOL using single-particle polarization information in the size range of $8-50 \mu \mathrm{m}$. Both of the methods show zero aspherical fraction during the liquid phase and a steep increase in the aspherical fraction during the glaciation process. After the full glaciation, the aspherical fraction determined from PPD-2K and CASDPOL varies between 0.95 and 1 , whereas the aspherical fractions from the NIXE-CAPS are somewhat lower, between 0.9 and 0.95 . The differences between the aspherical fractions of CAS-DPOL and NIXE-CAPS may stem from minor differences of the detectors and the differing methods to classify the particles asphericity as described in section 2. In the sublimation phase of the experiment, the methods show a similar decrease in the aspherical fractions, indicating an increasing presence of smooth sublimating frozen droplets.
The presented methods use the angular light-scattering properties to define aspherical particles. Another method for determining the aspherical fraction is to determine the particle asphericity from the CPI images. McFarquhar et al. (2013) used the area ratio $\alpha$ (i.e., the projected area of a particle divided by a circumscribed circle with diameter $D_{\max }$ ) as a measure for the particle sphericity and defined particles having $\alpha<0.8$ as aspherical. However, the problem with imaging methods is that small particles can appear spherical in the images, which leads to an underestimation of the aspherical fraction. Here, we defined the aspherical fraction from the PHIPS-HALO images based on the same method. We calculated the area ratio and applied a somewhat higher threshold of 0.9 to distinguish between spherical and aspherical particles. The aspherical fraction is illustrated by the orange curve in Fig. 4. As expected, the same trend is seen in the aspherical fraction; however, the maximum aspherical fraction after full glaciation is lower compared to the aspherical fractions derived from PPD-2K, NIXE-CAPS, and CAS-DPOL and varies between 0.5 and 0.7 .

Aspherical fraction is commonly used to distinguish between ice particles and water droplets in mixed-phase clouds, with the assumption that ice particles have a shape that differs from a sphere. In the case of vaporgrown cirrus clouds, this is usually the case; however, in convective systems the presence of smooth frozen droplets can potentially lead to a misinterpretation of the ice fraction, as the quasi-spherical ice particles can be misclassified as droplets. At the end of the sublimation period in the laboratory experiment, the automated algorithm of PPD-2K and the polarization-based measurements would have misclassified $80 \%$ of the ice particles 


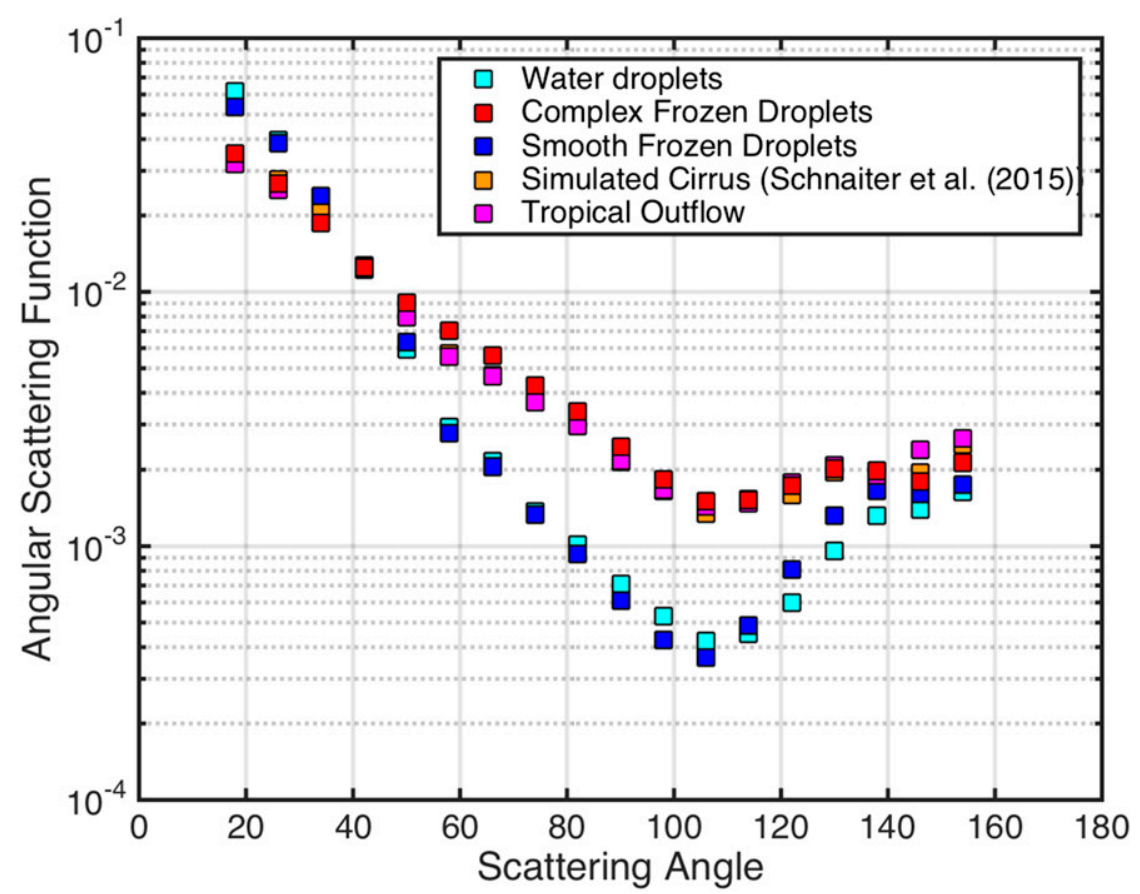

FIG. 7. Averaged angular scattering phase functions for water droplets (light blue squares), frozen droplets during their growth (red squares), frozen droplets at the end of the sublimation period (dark blue squares), roughened columns at $-50^{\circ} \mathrm{C}$ (orange squares; Schnaiter et al. 2016), and anvil outflow ice particles measured during ACRIDICON-CHUVA flight AC11 (magenta squares). The latter scattering phase function is averaged from all ice particles measured during anvil sampling between 1630 and 1642 UTC 16 Sep 2014. All the measurements in this figure were conducted with the PHIPS-HALO instrument.

as droplets; however, these methods performed well in the growth phase, when only complex frozen droplets were present. The analysis of the PHIPS-HALO images led to the largest uncertainty in the ice fraction, as the derived aspherical fractions were always below those derived from PPD-2K, NIXE-CAPS, or CAS-DPOL. The most sensitive method for distinguishing ice particles was the analysis of the PPD-2K diffraction patterns, as these patterns still contain information from the ice phase, even if the ice particles seem to be almost perfect spheres. Particle $\mathrm{v}$ in Fig. 2 is a diffraction pattern of a slightly deformed ice sphere that shows a somewhat elongated ring pattern and therefore can be identified as an ice particle. A visual inspection of the scattering patterns was performed (red line in Fig. 4). As a result of this procedure, a $100 \%$ aspherical fraction was measured during the growth of the ice particles, and, even at the end of the sublimation period, only $5 \%$ of the ice particles were misclassified as droplets.

\section{3) THE LINK BETWEEN THE MICROPHYSICAL AND OPTICAL PROPERTIES OF FROZEN DROPLETS}

The single-scattering properties of ice particles are dependent on their shape, size, and surface properties.
Aspherical and complex ice particles can increase the amount of light scattering into the backward hemisphere as compared to liquid droplets (e.g., Gayet et al. 1997; Ulanowski et al. 2006; Febvre et al. 2009; Cole et al. 2014) and therefore change the radiative properties of clouds. We investigated the angular lightscattering properties of the simulated convective clouds with two polar nephelometers (PN and PHIPS-HALO). The measured angular scattering functions were parameterized with the asymmetry parameter $g$ (black solid line in Fig. 4), which gives the degree of asymmetry of the scattering function with respect to the scattering angle of $90^{\circ}$. The measured $g$ values were strongly linked to the small-scale complexity of the frozen droplets. A maximum value for a asymmetry parameter of 0.85 was measured in the supercooled droplet cloud and a minimum value of 0.74 after the complete glaciation of the cloud, when the highest small-scale complexity was measured. Our observations are consistent with previous studies, where low asymmetry parameters have been detected in the case of roughened cirrus ice particles (Cole et al. 2014; Schnaiter et al. 2016). In the sublimation period, $g$ was observed to increase as the small-scale complexity of the frozen droplets decreased. 

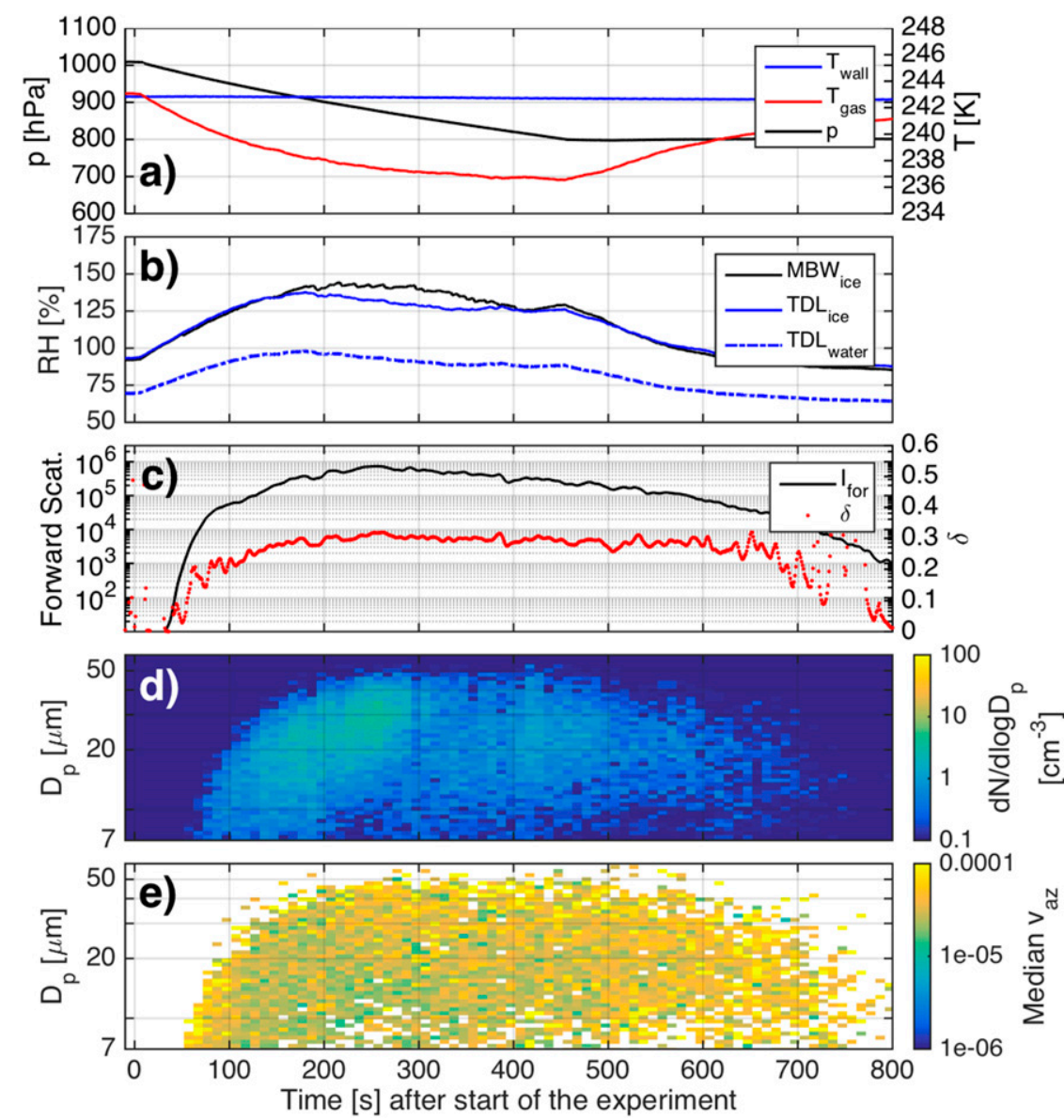

FIG. 8. Simulation of a convective system, where the ice particles nucleate through vapor phase (experiment 24). The experiment was started with $16 \mathrm{~cm}^{3}$ of Argentinean soil dust particles and a pumping speed of $60 \%$ that led to an initial cooling rate of $-1.5 \mathrm{~K} \mathrm{~min}^{-1}$. (a) The pressure of the chamber (black line) as well as the chamber and wall temperatures (red and blue lines, respectively). (b) The total water measured with MBW (black line) and the interstitial water with respect to ice (blue solid line) and water (blue dashed line) measured with TDL. (c) The forward-scattering intensity (black line) and the depolarization ratio were measured for cloud particles in the middle of the chamber. (d) The PPD-2K size distribution. (e) The sizesegregated median variance of the $2 \mathrm{D}$ scattering patterns.

Almost the same value for $g$ was reached at the end of the experiment as was measured for the initial liquid droplet cloud, hence confirming the previous observations that the sublimating frozen droplets can behave optically equivalent to spheres.

Figure 7 highlights the dramatic effect that smallscale complexity has on the averaged angular scattering properties of frozen droplets. The averaged angular scattering function of roughened frozen droplets measured in laboratory simulations (red squares in Fig. 7) is smooth, featureless at scattering angles less than $100^{\circ}$, and has an enhanced scattering intensity in the backward hemisphere. Interestingly, the averaged scattering response of the complex frozen droplets does not significantly differ from that of complex columns measured in simulated cirrus clouds (orange squares; Schnaiter et al. 2016). In these two laboratory simulations, it is difficult to identify the underlying shape of the ice particles from the averaged scattering phase function, but instead the crystal complexity seems to dominate the average scattering properties.

If the frost layer is sublimated from the surface of the frozen droplets, they scatter light similar to water droplets (dark blue squares in Fig. 7) and show dropletlike features: that is, a minimum between $100^{\circ}$ and $120^{\circ}$ and a rainbow-like feature (in this case ice bow) around $140^{\circ}$. Similarly, Gayet et al. (2012a) observed an icebow-like feature around the same angle for nearspherical ice particles at the top of a convective storm. 


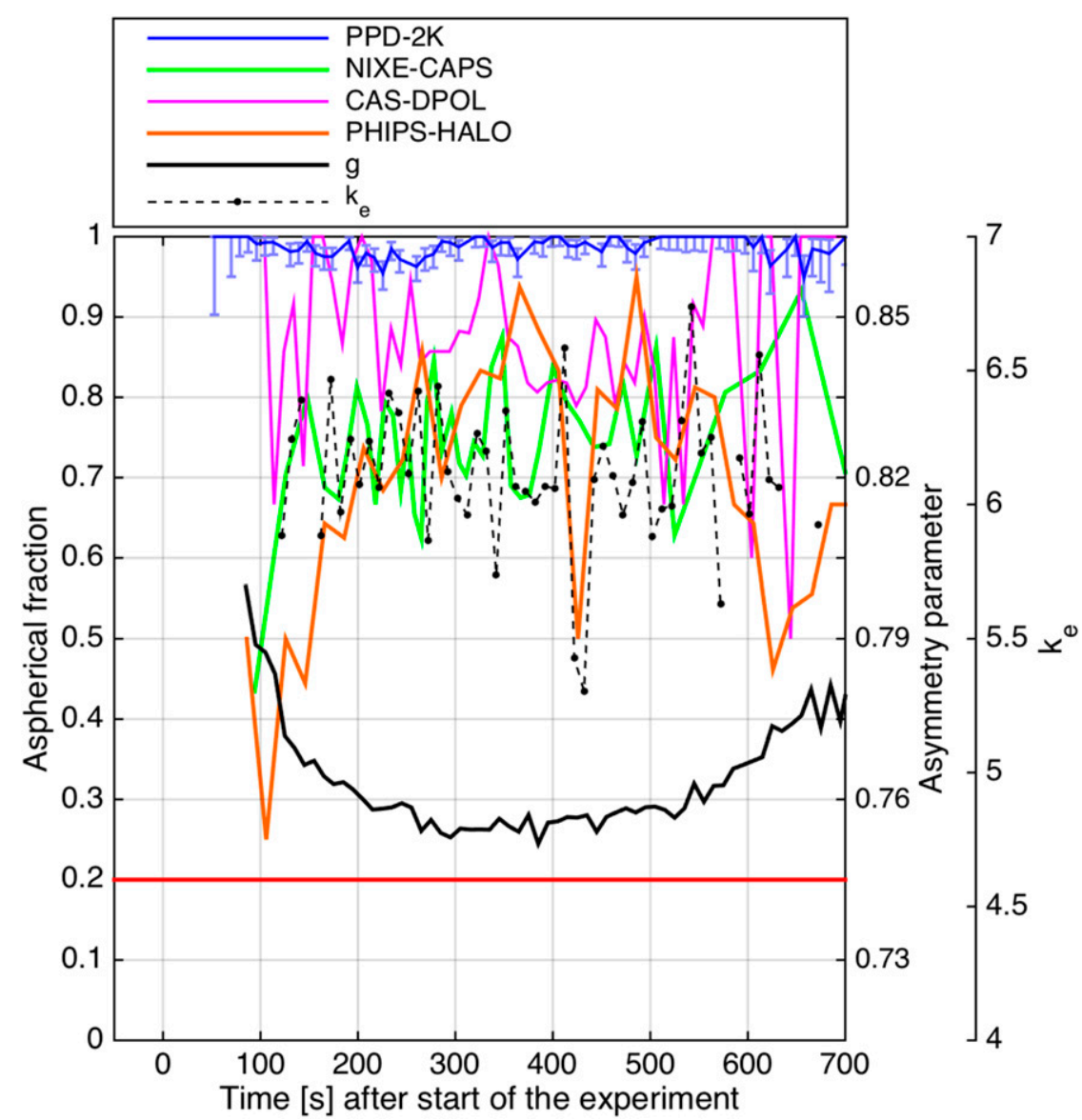

FIG. 9. Aspherical fractions during experiment 24 (Fig. 6) PPD-2K (blue line), NIXE-CAPS (green line), and CAS-DPOL (magenta line). Also shown are the asymmetry parameter $g$ (black solid line) determined from PN measurements and the complexity parameter $k_{e}$ (black dashed line) determined from SID-3 measurements.

Baran et al. (2012) was able to explain this feature by assuming independent quasi-spherical ice particles. Surprisingly, the ice-bow-like feature is also observed in the case of the complex frozen droplets, but with a peak around $130^{\circ}$. This shift in the ice bow can be modeled by increasing the distortion of the quasispherical model particles (Baran et al. 2012). Baran et al. (2012) also argued that the underlying spherical shape of the ice particles can survive the addition of surface roughness or distortion. However, an ice bow was also observed in the study of Schnaiter et al. (2016) (orange squares in Fig. 7), which could indicate a more universal feature in ice clouds that is not only related to spherical ice particles.

\section{b. Ice particle formation through vapor phase}

In this section, the optical and microphysical properties of ice particles formed by the deposition nucleation mode are discussed. The experiment procedure was identical to what is presented in section $3 \mathrm{a}$, with the exception that Argentinean soil dust was used as heterogeneous ice nuclei. The first ice particles were formed at experiment time $32 \mathrm{~s}$, when a temperature of $242 \mathrm{~K}$ and $S_{\text {ice }}$ of 1.03 were reached (Fig. 8b), indicating the high nucleation activity of this specific dust sample. The formation of the cloud is seen in the increase in the forward-scattering signal, and the depolarization ratio above zero confirms the presence of ice particles (Fig. 8c). Water saturation was not reached during this experiment, and therefore all the ice particles were nucleated and grown through the vapor phase. The nucleation spectrum of the soil dust was rather wide, which led to a broad ice size distribution measured by PPD-2K in Fig. 8d; small (below $10 \mu \mathrm{m}$ ) and larger (up to $50 \mu \mathrm{m}$ ) ice particles coexisted throughout the experiment. At experiment time $455 \mathrm{~s}$, the expansion was stopped, and the ice particles were allowed to sublimate. 

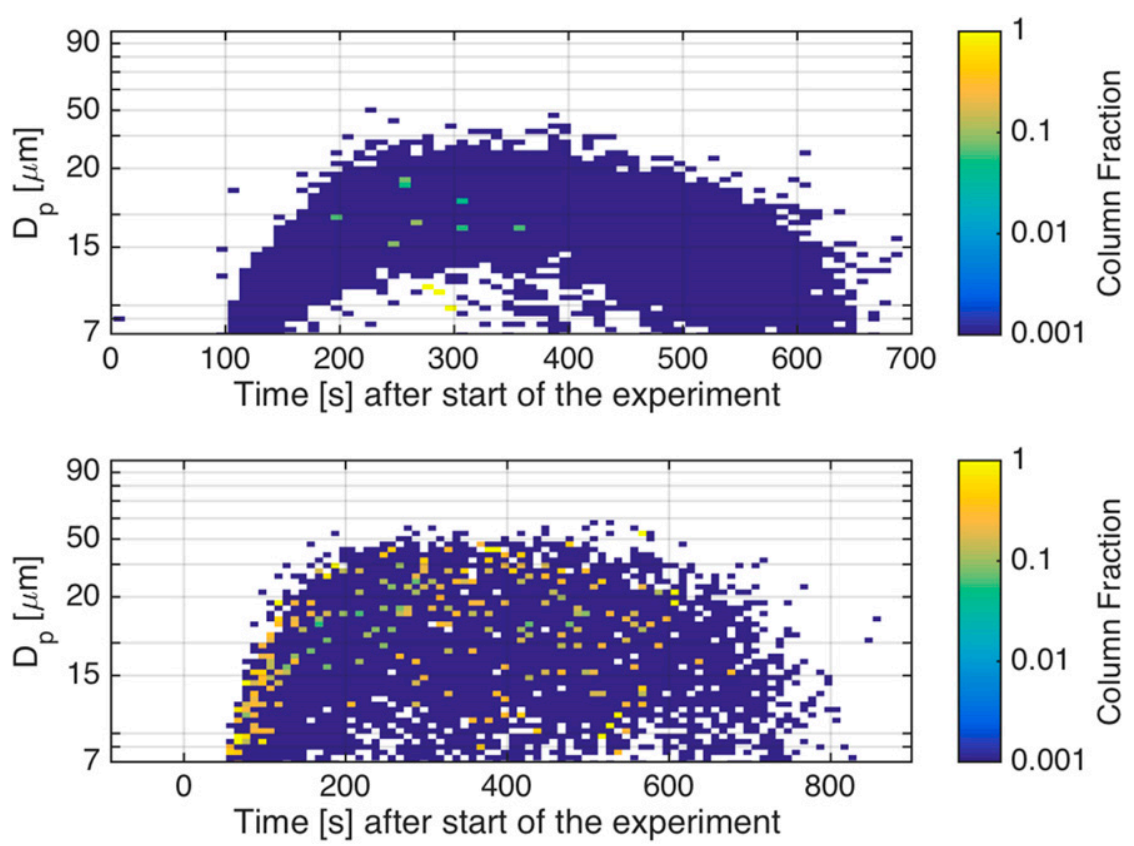

FIG. 10. Calculated column fractions based on PPD-2K measurements for (top) experiment 17 and (bottom) experiment 24. During experiment 17, the ice particles are classified as irregular, and no signs of hexagonal shapes are found. During experiment 24 , the first ice crystals formed in deposition nucleation at low $S_{\text {ice }}$ and grew to columnar shape. At the later stage of the experiment, more irregular ice crystal habits were observed.

A significantly different trend in the ice microphysical and optical properties was observed as compared to the ice cloud formed by droplet freezing (Figs. 8 and 9). The PPD-2K variance analysis gave no evidence of spherical ice particles (Fig. 8e), and, consequently, a constant aspherical fraction close to 1 was measured (Fig. 9). The aspherical fraction measured by NIXECAPS and CAS-DPOL was clearly lower, around 0.70.8 . This difference is much larger than the difference between PPD-2K and the polarization-based measurements of the previous experiment (Fig. 3). The aspherical fraction determined from the PHIPS-HALO images was now higher and comparable to the polarizationbased measurements after the ice particles had reached their maximum size. Possible explanations for the differences in the aspherical fractions are different ice microphysical properties and a broader particle size distribution in case of heterogeneously nucleated ice particles.

Moreover, the $k_{e}$ value stayed constant, having a mean value of 6.1. This value was slightly lower than what was measured for the growing frozen droplets in section 3a. The difference in the small-scale complexity can be explained with the ice-growing conditions (Schnaiter et al. 2016), since the vapor-grown ice particles grew at lower ice saturation than the ice formed through the liquid phase. The first ice particles, grown at the lowest supersaturation, were observed to have pristine columnar shape (Fig. 10), but as $S_{\text {ice }}$ was constantly increasing, the majority of the ice crystals grew complex. Furthermore, the variation in $g$ was significantly lower than in the previous experiment; a relatively high $g$ of 0.8 was measured at the beginning, when pristine columns were present, but that later quickly decreased to values between 0.76 and 0.75 . Thereafter, only little variation was observed before the end of the sublimation period, when $g$ increased to 0.78 . However, $g$ over 0.8 was never observed in this experiment, indicating that the angular scattering function clearly resembled what is expected for aspherical ice particles. Also the depolarization ratio was observed to remain constant around 0.3 throughout the experiment. The constant depolarization ratio together with the analysis of the scattering patterns and the $g$ value showed that the ice particles that were heterogeneously nucleated and grown through the vapor phase remained nonspherical and had optical properties that were rather constant (largest variation was observed in $g$ ) throughout the growth and sublimation.

\section{Case study of a midlatitude convective system during MACPEX}

Measurements in a midlatitude convective system were performed over Texas on 21 April 2011 during 


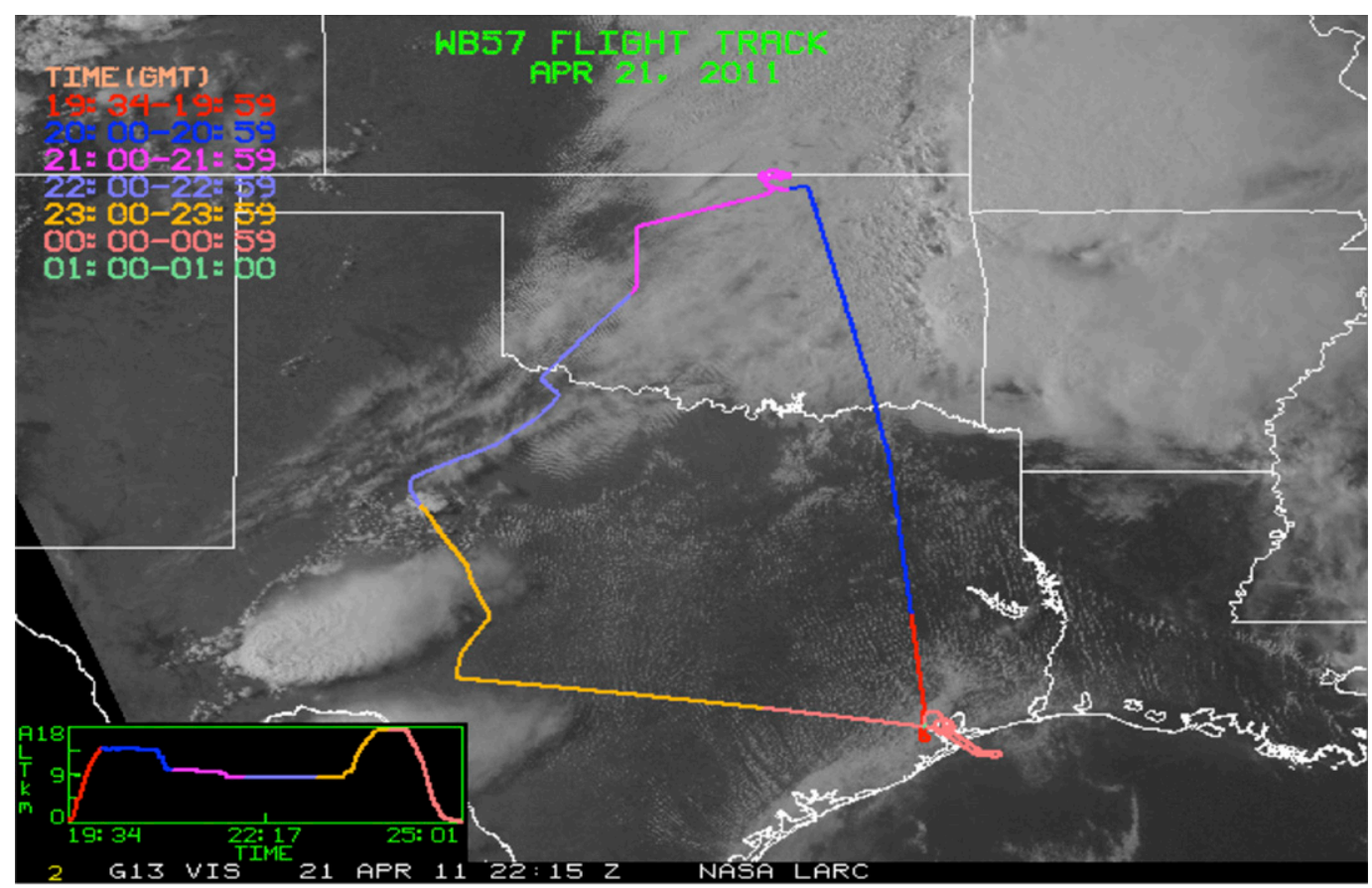

FIG. 11. The flight path of the NASA WB-57 aircraft superimposed on a satellite image. The anvil sampling was conducted between 2300 and 2359 UTC, marked with an orange color. The two convective systems are seen in the bottom-left corner of the satellite image.

the Midlatitude Airborne Cirrus Properties Experiment (MACPEX) campaign using the NASA WB-57 aircraft. On that day, two convective systems had developed over western Texas and northern Mexico, and the anvil outflow from these two systems extended $\sim 100 \mathrm{~km}$ east toward central Texas. Figure 11 shows the flight path of the WB-57 over a satellite image. The measurements in anvil outflows were conducted between 2300 and 2359 UTC (flight path marked in orange). The WB-57 flew first under the northern anvil at an altitude of $9 \mathrm{~km}$, sampling the lower part of the outflow. At 2322 UTC, the aircraft ascended through the anvil outflow, exiting at an altitude of $13.5 \mathrm{~km}$. The temperature at the lower parts of the anvil was $239 \mathrm{~K}$, and a temperature of $212 \mathrm{~K}$ was reached at the upper part of the anvil.

The anvil profile during the ascent shows an increase in the sub-40- $\mu \mathrm{m}$ ice particle concentrations from 3.5 to $10 \mathrm{~cm}^{-3}$ (Fig. 12a). Particularly small ice crystals in the sub-20- $\mu \mathrm{m}$ size range are found at the top of the convective system (Fig. 12b). Although the ice particle concentrations are significantly larger than normally measured in cirrus clouds (Lawson et al. 2006; Krämer et al. 2009), they compare well to what was previously measured in the anvil of a midlatitude storm (Gayet et al. 2012a; Stith et al. 2014). An inspection of the CPI images (Fig. 13) revealed the presence of small ice particles with a distinct signature of frozen droplets. Approximately $84 \%$ of all the CPI observed particles were classified as single frozen droplets and $2.2 \%$ as aggregates of frozen droplets. The high fraction of frozen droplets indicate that the majority of the ice particles were formed through liquid phase in the mixed-phase region of the convective cell, from where they were transported to the anvil region in the updraft, forming the dominant particle type. The high fraction of frozen droplets is in agreement with previous studies of midlatitude convective systems (Gayet et al. 2012a; Stith et al. 2014).

The water vapor measurements during the anvil sampling from the NASA diode laser hygrometer (DLH; Diskin et al. 2002) show that most of the time the frozen droplets were found in ice-subsaturated conditions (black points in Fig. 12a). Especially strong subsaturated conditions were measured around 2330 UTC, when $S_{\text {ice }}$ reached 0.6. The subsaturated conditions together with the high concentration of small ice particles give evidence that these ice particles had formed almost simultaneously in a vigorous updraft and thus quickly depleted the available water vapor. This depletion of the $\mathrm{H}_{2} \mathrm{O}$ vapor obviously prevented further ice particle growth, and as a consequence they remained small. The same phenomenon was also observed in the AIDA cloud chamber simulation (section $3 \mathrm{a}$ ): after the cloud was 

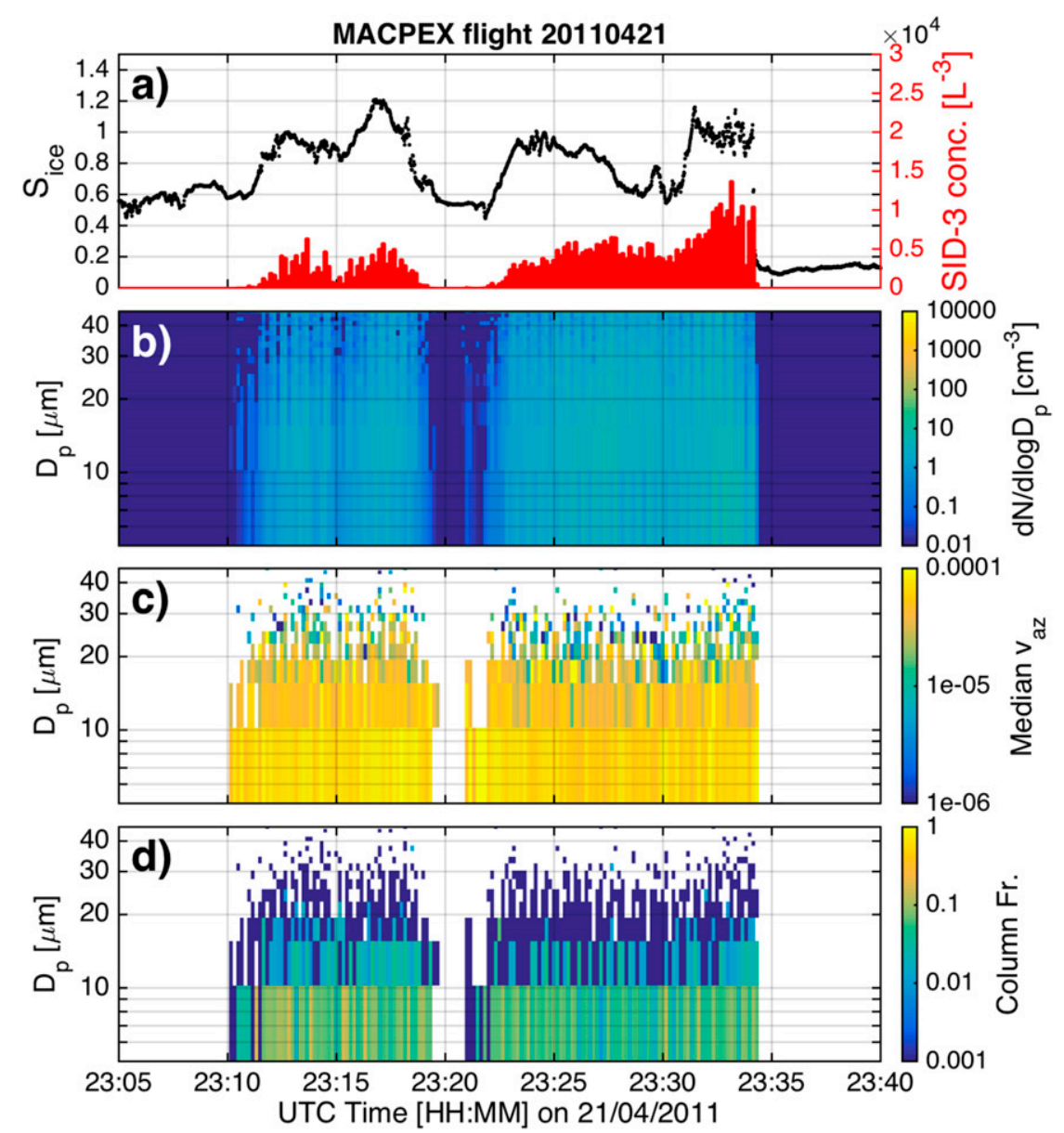

FIG. 12. SID-3 and water vapor measurements during anvil sampling on 21 Apr 2011. (a) The total concentration for particles between 5 and $45 \mu \mathrm{m}$ and $S_{\text {ice }}$. (b) The particle size distribution. (c) The size-segregated variance analysis results. (d) The size-segregated column fraction.

glaciated, $S_{\text {ice }}$ started to quickly decrease, although the chamber cooling was continued.

The results from the chamber experiments indicate that the majority of the frozen droplets measured by the CPI during the MACPEX flight should have been sublimating, and we would expect to see spherical ice particles appear. An inspection of the SID-3 diffraction patterns indeed shows signatures of spherical particles. Two types of ring patterns were observed. First, SID-3 images with clear ring patterns were seen (Fig. 14a), similar to the observation in the laboratory in the case of sublimating frozen droplets (section 3a). Second, patterns with underlying concentric rings with somewhat bended lines crossing the patterns were observed (Fig. 15). With the help of 2D Fourier transform simulations, we were able to identify that these patterns were the result of aggregation. Figure 15 shows simulations for a double aggregate, a triple aggregate, and an aggregate of 10 spheres. The size of the spheres was kept constant, and the light diffraction was simulated at the angular range of the SID-3 instrument. Despite the increase in the complexity due to aggregation, the underlying concentric-ring pattern does not seem to disappear, but an additional structure is added inside the rings. The double aggregates show a unique pattern that can be easily identified from the SID-3 measurements, but as the number of spheres in the aggregates increases, the patterns become more difficult to identify, and they are not distinguishable from complex ice crystals. We were successful in identifying double aggregates and a few triple aggregates form the MACPEX dataset (bottom row in Fig. 15).

The presence of sublimating frozen droplets was also confirmed with the automated variance analysis that showed low $v_{\mathrm{az}}$ values for ice particles around $20 \mu \mathrm{m}$ (Fig. 12c). The size of the smooth frozen droplets seen 


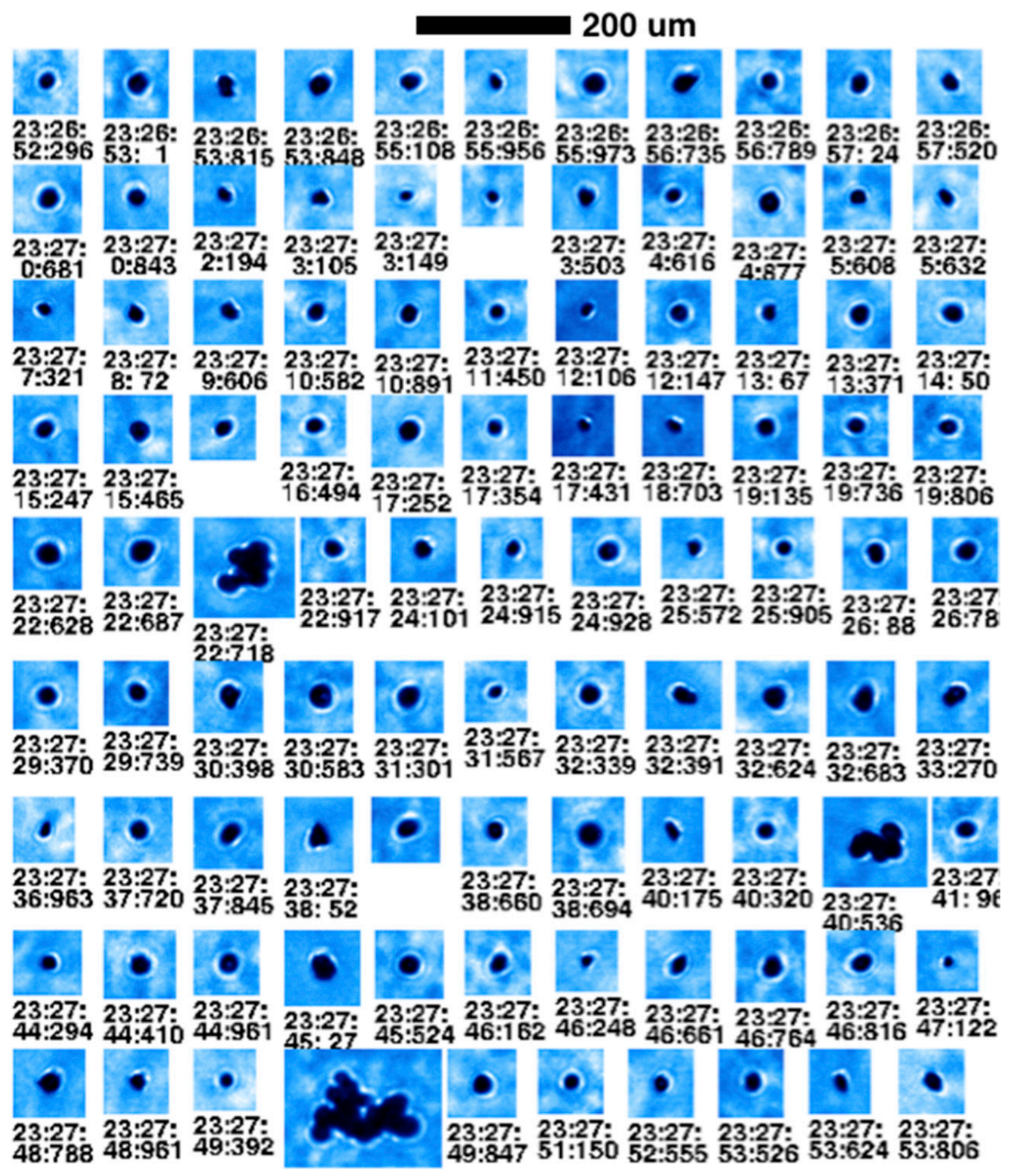

FIG. 13. A collection of ice particles imaged with 3V-CPI in the convective outflow during MACPEX. Mainly single frozen droplets were detected with few aggregates of frozen droplets.

by SID-3 is comparable to the size of the frozen droplets seen in CPI images, and the measured frozen droplet sizes also agree with previous observations (Baran et al. 2012; Stith et al. 2014). The smallest, sub-20- $\mu \mathrm{m}$, anvil-outflow ice particles were observed to be aspherical (high $v_{\text {az }}$ in Fig. 12c), with indications of columnar shape (Fig. 12d). The origin of these small aspherical particles is not clear. Although columnar, these small 

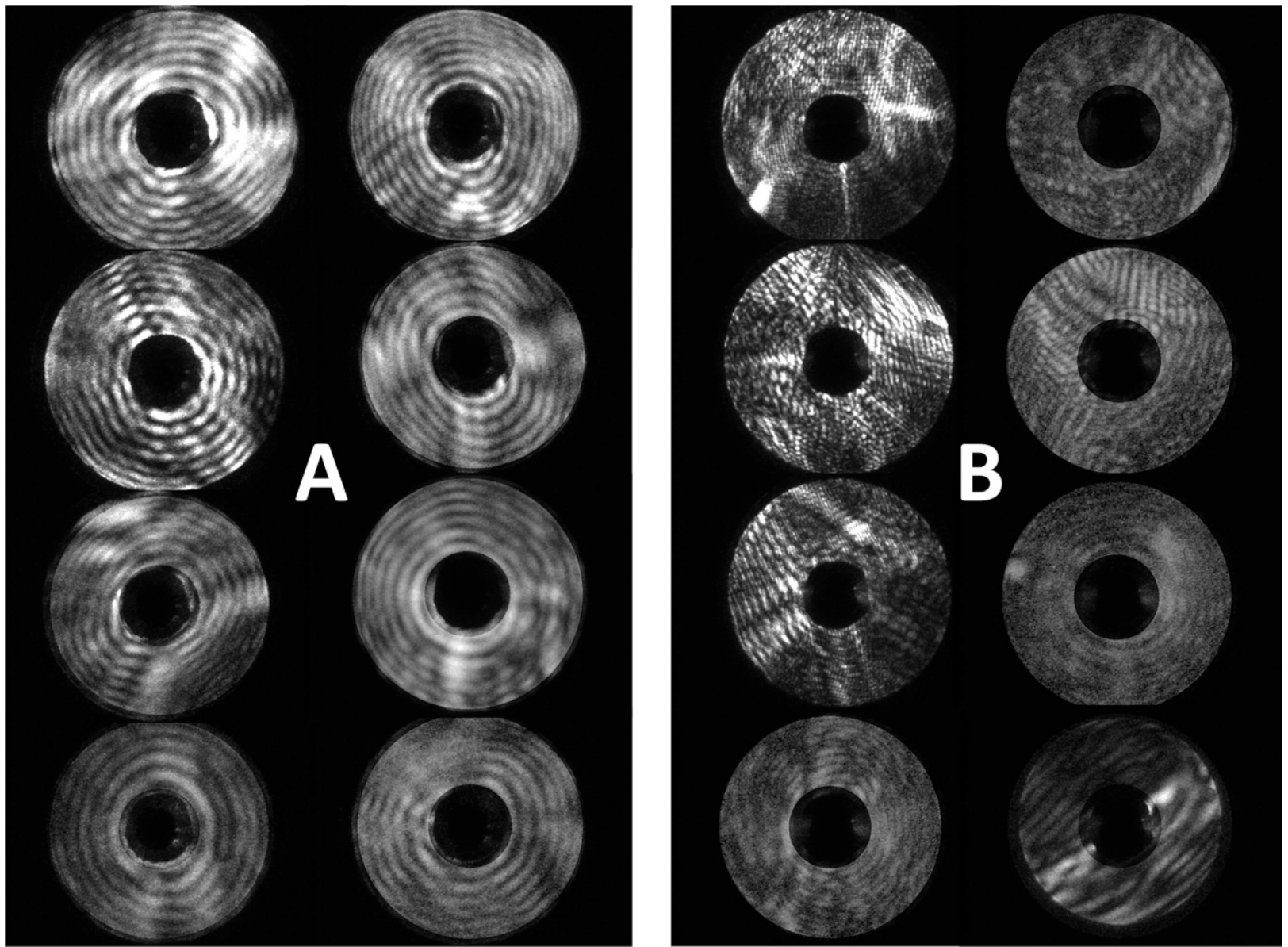

FIG. 14. Examples of single-particle diffraction patterns measured in convective outflow during (a) the MACPEX flight on 21 Apr 2011 and (b) ACRIDICON-CHUVA flight AC11 on 16 Sep 2014. While during MACPEX the frozen droplets were found to be sublimating, the majority of the ice particles measured during ACRIDICON-CHUVA were found in supersaturated conditions.

particles show a high degree of complexity. It is possible that these particles have formed in situ through the vapor phase in the later phase of the convection and therefore do not appear spherical in subsaturated conditions, as seen in the simulated cloud in section $3 \mathrm{~b}$.

\section{Case study of a tropical convective system during ACRIDICON-CHUVA}

Measurements in a tropical convective system were carried out during the Aerosol, Cloud, Precipitation, and Radiation Interactions and Dynamics of Convective Cloud Systems-Cloud Processes of the Main Precipitation Systems in Brazil: A Contribution to Cloud Resolving Modeling and to Global Precipitation Measurement campaign [ACRIDICON-CHUVA; see details for the ACRIDICON part of the campaign in Wendisch et al. (2016)], where airborne observations were done with the HALO aircraft. On 16 September
2014, convective systems were targeted over the Amazonian rain forest. Developing convective systems were observed northwest of Manaus, and the HALO aircraft reached the area of outflows about $1.5 \mathrm{~h}$ after their formation. The HALO aircraft traversed two separate outflows from north to south at an altitude of $12.7 \mathrm{~km}$. The total particle number concentration is shown in Fig. 16a and the particle size distribution during the anvil sampling in Fig. 16b. The maximum particle number concentration was $2.3 \mathrm{~cm}^{-3}$, but, on average, particle concentrations were found to be below $1 \mathrm{~cm}^{-3}$. The size distribution shows that the majority of the sub-50- $\mu \mathrm{m}$ particles are found below $20 \mu \mathrm{m}$.

Visual inspection of the PHIPS-HALO images reveals a significant amount of small ice particles (Fig. 17). Overall, 23\% of the imaged ice particles were classified as frozen droplets and $19 \%$ as other small $(<50 \mu \mathrm{m})$ irregular ice particles. With smaller 

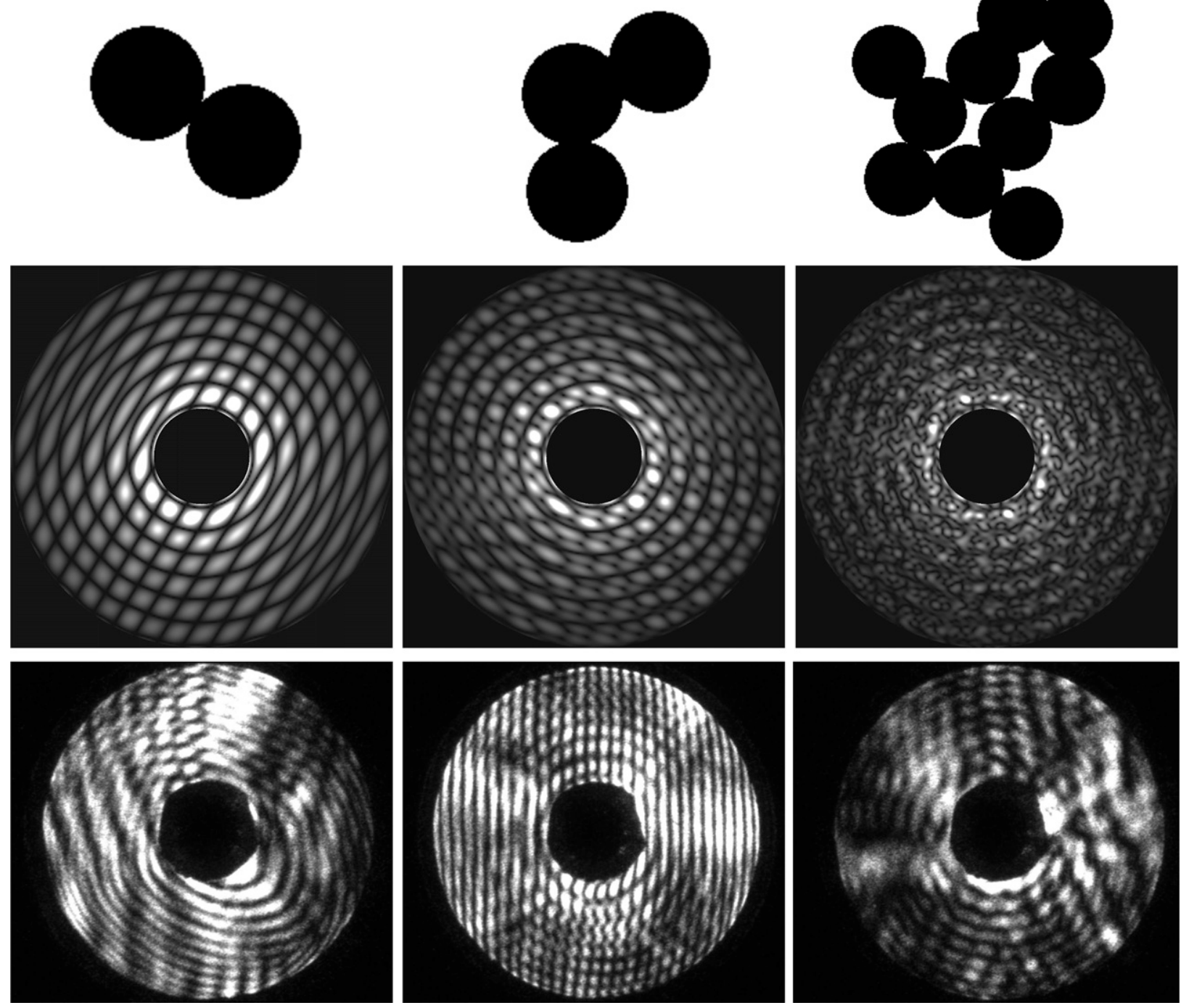

FIG. 15. Simulation of diffraction patterns from frozen droplet aggregates using 2D Fourier transform on idealized ice spheres. (top) Simulations were made for aggregates of 2,3, and 10 spheres, where the sizes of the individual spheres were kept constant. (middle) The simulation results. (bottom) Diffraction patterns of real aggregated frozen droplets found in a convective outflow over Texas during the MACPEX campaign.

fractions were observed plates $(9 \%)$, bullet rosettes $(14 \%)$, columns $(3 \%)$, and aggregated ice particles (15\%). The RH conditions were measured with the Sophisticated Hygrometer for Atmospheric Research (SHARC) in situ tunable diode laser hygrometer. Slightly supersaturated or near-ice-saturated conditions were observed throughout the sampling (Fig. 16a), so it can be expected that the ice particles were not sublimating. Therefore, it is no surprise that the SID-3 diffraction patterns (Fig. 14b) or the variance analysis (Fig. 16c) do not show indications of sublimating frozen droplets, but the ice particles were found to be rough and irregular. The smallest ice particles were found to have indications of a hexagonal shape, similar to the convective outflow during MACPEX.

The angular scattering function was measured simultaneously with PHIPS-HALO. We averaged the angular scattering functions of individual ice particles to form an averaged angular scattering function for the cloud. This average scattering function is almost identical to the scattering phase function measured in the laboratory for rough frozen droplets (Fig. 7): that is, it is smooth and features up to a scattering angle of $100^{\circ}$ and an enhanced scattering to the backward hemisphere. An ice-bow-like feature is seen around $130^{\circ}$, similar to rough frozen droplets or roughened columns. Some differences are seen in the scattering 

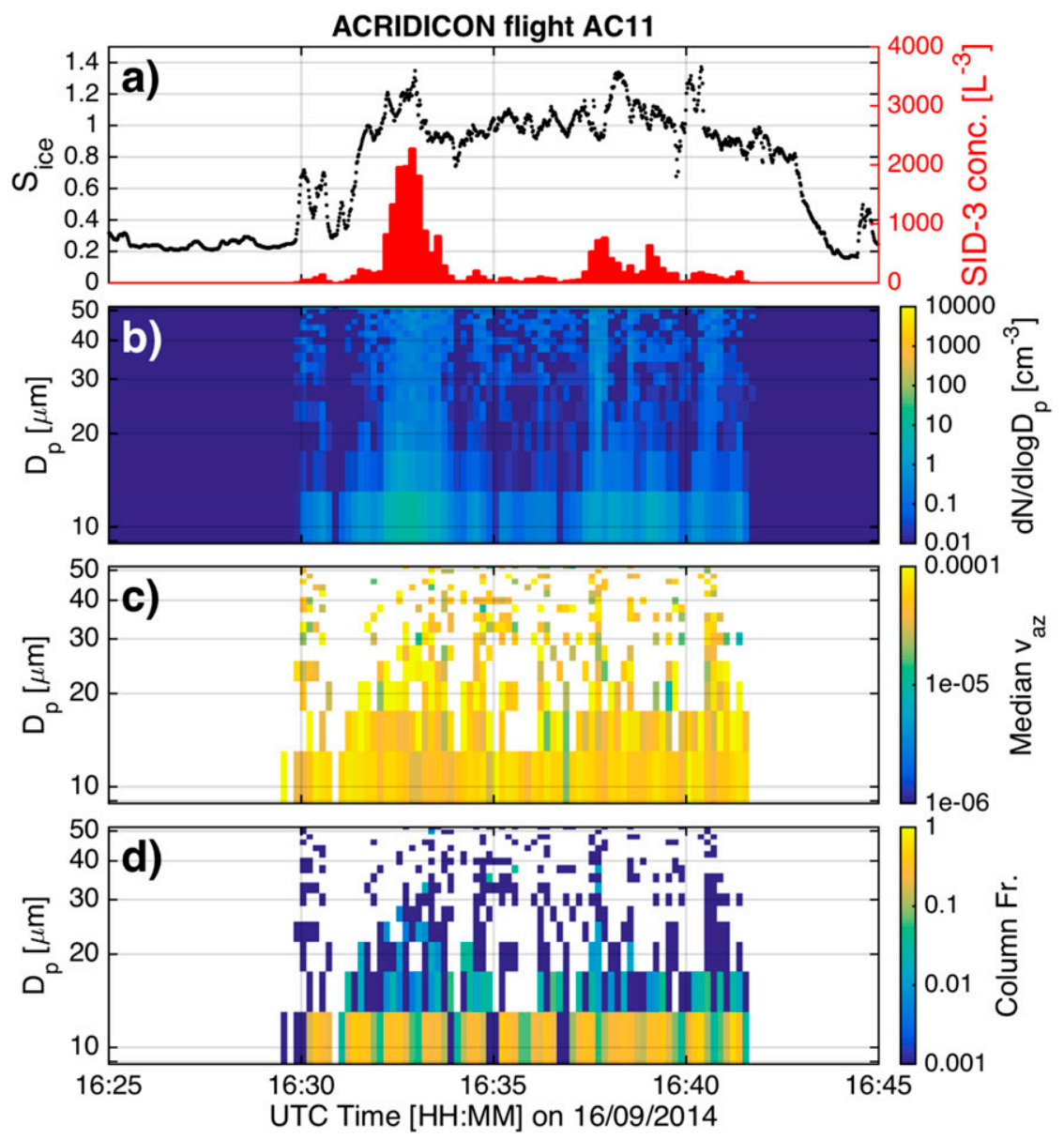

FIG. 16. SID-3 and water vapor measurements during anvil sampling on 16 Sep 2014. (a) The total concentration for particles between 7 and $50 \mu \mathrm{m}$ and $S_{\text {ice }}$. (b) The particle size distribution. (c) The size-segregated variance analysis results. (d) The size-segregated column fraction.

behavior between $50^{\circ}$ and $100^{\circ}$ and at scattering angles greater than $146^{\circ}$, but this can be explained by the presence of other particle habits.

\section{Atmospheric implications}

The difference in the angular scattering function of roughened and smooth frozen droplets (Fig. 7) illustrates the uncertainty in the scattering properties of small quasispherical ice particles. The impact of frozen drops on climate is governed by their frequency and the environmental conditions they are found in. This study, together with previous studies in midlatitude convective systems (Lawson et al. 2003; Gayet et al. 2012a; Stith et al. 2014), indicates that frozen droplets are abundant in midlatitude convective outflows and, therefore, that they are important for their radiative properties. In tropical outflows, other particle types seem to be more frequent (Lawson et al. 2003; Connolly et al. 2005; Frey et al. 2011), although we were able to detect frozen droplets in convective outflow of a cumulonimbus cloud over Brazil.

Independent of the location, we can expect that frozen droplets have a high degree of complexity if found in supersaturated environmental conditions and, therefore, have a flat angular scattering function and a low asymmetry parameter. In this study, such a scattering phase function was measured in a tropical outflow (Fig. 7), and in a study of Gayet et al. (2012a), the authors reported a relatively low asymmetry parameter of 0.776 for ice particles at the top of a convective storm. In both cases, mostly ice supersaturated conditions were observed.

However, ice particles are frequently found in subsaturated regions (e.g., Krämer et al. 2009). In laboratory experiments, we showed that in sublimation the frozen droplets can become smooth and optically spherical. Gayet et al. (2012a) reported an increase in the asymmetry parameter in the later phase of the 


\section{$\longrightarrow 100 \mu \mathrm{m}$}
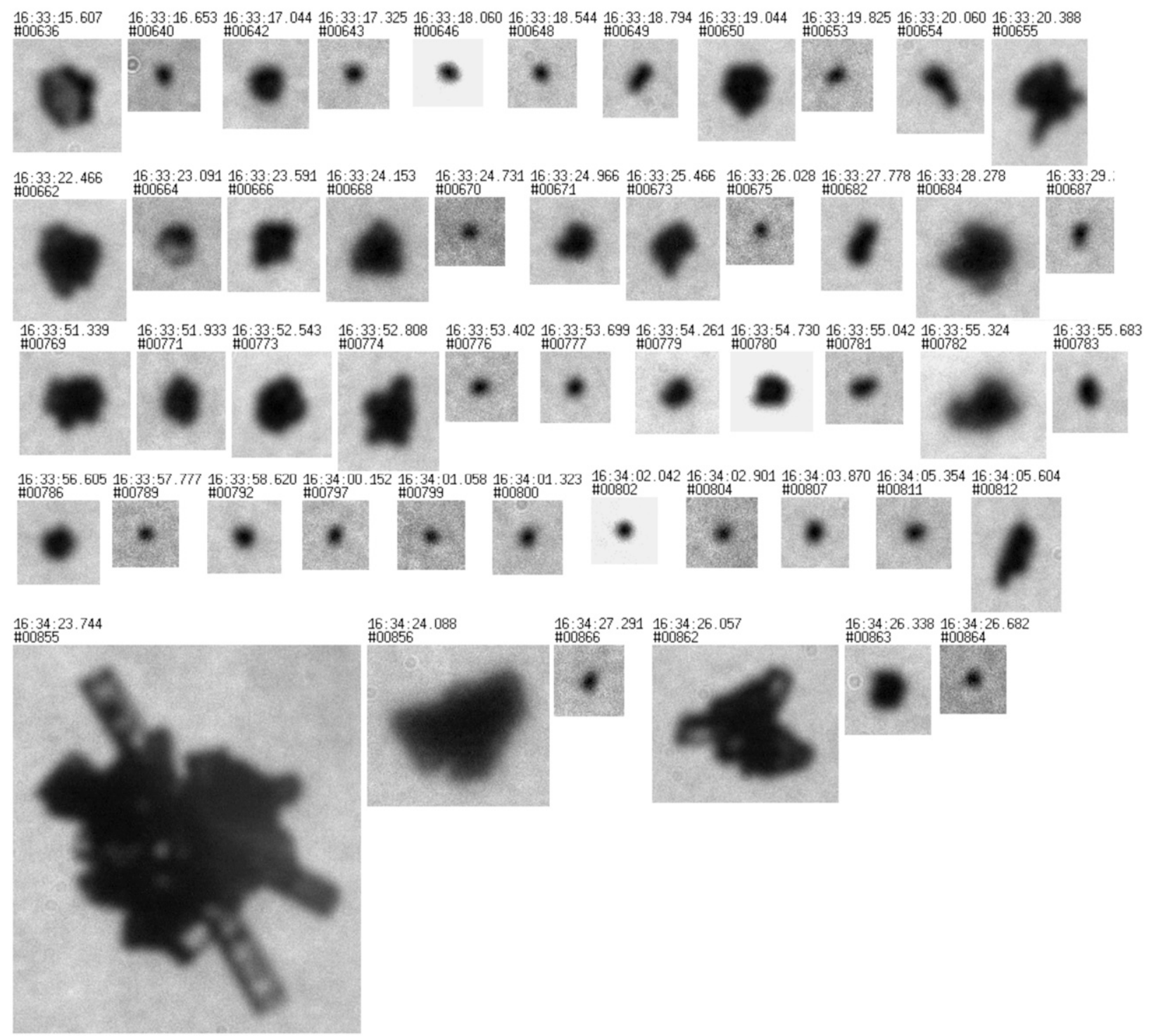

$16: 34: 24.088$
$\# 00856$

$\begin{array}{ll}16: 34: 27.291 & 16: 34: 26.057 \\ \# 00866 & \# 00862\end{array}$ $16: 34: 26.338$
$\# 00863$
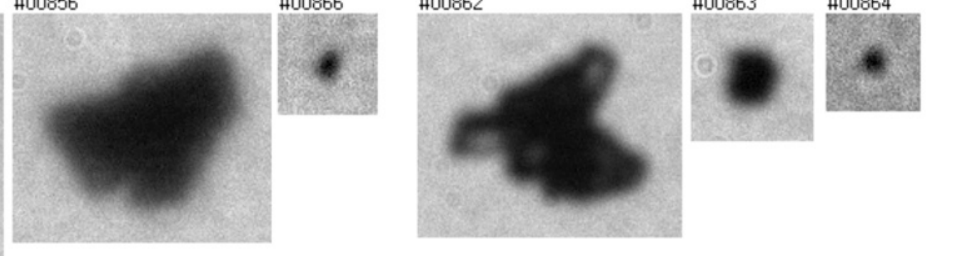

FIG. 17. A collection of ice particles imaged with PHIPS-HALO in a tropical outflow anvil. In this particular case, a significant fraction of small ice particles was detected. Other observed habits were plates, aggregates of plates, and bullet rosettes.

measurements in the convective outflow that was linked with sublimation of the ice particles. During MACPEX, optically spherical ice particles were observed from SID-3 measurements, and the presence of these particles could have led to a similar increase in the cloudaveraged asymmetry parameter compared to what was reported in Gayet et al. (2012a) if simultaneous polar nephelometer measurements would have been available. Until now, polar nephelometer measurements in outflows have only been reported in a few cases; therefore, it is impossible to predict the role of quasi-spherical frozen droplets in the radiative properties of convective clouds. A clear need for simultaneous scattering and detailed microphysical measurements is evident, especially in midlatitude convective outflows, where sublimating frozen droplets can be expected.

Besides in anvil outflows, frozen droplets can also be found in contrails. Contrails are formed when liquid water droplets form by condensation of water vapor mainly on soot and volatile particles in an exhaust plume (Schumann 2005; Kärcher and Yu 2009). In the colder and humid upper troposphere, the droplets freeze and 
form a visible contrail, which spreads out and becomes persistent at ice supersaturated conditions. Although contrail cirrus is outside the scope of this paper, our laboratory results can also help to understand observations made in young contrails in studies of Febvre et al. (2009) and Gayet et al. (2012b). Febvre et al. (2009) found that young (about $2.5 \mathrm{~min}$ of age) contrails have a high asymmetry parameter ( 0.827 ) compared to aged (about $20 \mathrm{~min}$ of age) contrails (0.787). Similar behavior was found from experiments during the Contrail and Cirrus Experiment (CONCERT) campaign (Voigt et al. 2010) in the aging contrail from an A380 aircraft by Gayet et al. (2012b). A decrease in the asymmetry parameter from 0.88 to 0.8 was observed already within the first $5 \mathrm{~min}$ of contrail evolution. These observations were associated and interpreted with an increasing fraction of aspherical particles, as no other information on particle complexity was available at that time: "Unfortunately, the transition from quasi-spherical shapes to irregular ice particles in the atmosphere is poorly understood" (Febvre et al. 2009, p. 10). The laboratory results shown in this paper might help to explain the transformation from spherical ice to aspherical (or roughened) ice. Since supersaturated conditions are necessary for formation of an aged contrail, our results would indicate that the ice particles found in aged contrails are roughened or complex compared to the newly formed contrail ice particles that have not yet developed crystal complexity. Specifically, the change in the scattering intensity in the backward hemisphere observed by Febvre et al. (2009) and Gayet et al. (2012b) is comparable to what was simulated in laboratory. Therefore, as with convective outflows, the radiative properties of contrails might be governed by the degree of complexity of small ice crystals.

\section{Conclusions}

Small quasi-spherical ice particles are proposed to have an important role in determining the radiative properties of midlatitude convective outflows. However, their microphysical and scattering properties are only vaguely known. In this paper, the microphysical and optical properties of these ice particles were studied in cloud chamber simulations. We employed a new method to study the ice particle complexity along with their asphericity based on analysis of 2D diffraction patterns measured with the SID-3 and PPD-2K instruments. With simultaneous polar nephelometer measurements, we were able to find a link between the microphysical and radiative properties of the simulated ice particles. The following four major conclusions can be drawn from the chamber experiments:
1) It is possible to discriminate between optically spherical and quasi-spherical ice particles based on their 2D diffraction patterns.

2) The microphysics of these particles can vary strongly: a high degree of complexity is developed during the formation and initial growth of the frozen droplets in mixed-phase cloud. This complexity can be removed in sublimation, and the resulting ice particles resemble smooth spheres.

3) The complex or roughened frozen droplets have a low asymmetry parameter and show a flat scattering phase function that does not significantly differ from that measured for other ice clouds composed of roughened ice particles.

4) The sublimating frozen droplets have a high asymmetry parameter, and they can act optically similarly to water droplets.

In fact, a maximum difference in the angular lightscattering properties is observed, mainly as a result of the change in the frozen droplet surface properties. Therefore, the scattering properties of these particles are highly uncertain and need to be addressed in future field measurements.

We applied the methods developed in the laboratory in two aircraft campaigns in midlatitude and tropical convective outflows. In the midlatitude system, single frozen droplets were found to be the dominant ice particle type. Subsaturated conditions were recorded, and this led to sublimation of the frozen droplets. Consistent with the laboratory simulations, the measured SID-3 diffraction patterns showed indications of sublimating and smooth ice spheres, which could indicate that the cloud radiative properties might be affected by optically spherical ice. However, polar nephelometer measurements were not available to validate this. We were also able to locate frozen droplets in a tropical convective system. The ice particles were found in supersaturated conditions or near ice saturation, and, therefore, no indications of smooth ice spheres were found. The average angular scattering function measured during the anvil sampling was similar to what was measured in laboratory for complex frozen droplets. In conclusion, the results from the two case studies in natural convective systems were consistent with the laboratory measurements of simulated convective systems.

Acknowledgments. We gratefully acknowledge the DLH instrument group for providing the RH measurements during the MACPEX campaign and Martin Zöger and his team from German Aerospace Center for providing the RH data during the ACRIDICON-CHUVA campaign. 
Pat Minnis and his group at LaRC are acknowledged for gathering the satellite data during MACPEX. The AIDA experiments would not have been possible without the support of the AIDA technical team, and their work is kindly acknowledged. This research has received funding from the Seventh Framework Programme of the European Union (Marie CurieNetworks for Initial Training MC-ITN CLOUD-TRAIN 316662) and from the German Research Foundation within the HALO priority program 1294 (Grant SCHN 1140/1-2). MACPEX SID-3 measurements were partially supported by the NASA MACPEX research project funding, Hal Maring program manager, under Contract NNX11AC07G. The original images from the SID-3, PPD-2K, and PHIPS-HALO used in this work will be available upon request from the corresponding author.

\section{REFERENCES}

Abdelmonem, A., E. Järvinen, D. Duft, E. Hirst, S. Vogt, T. Leisner, and M. Schnaiter, 2016: PHIPS-HALO: The airborne particle habit imaging and polar scattering probe. Part I: Design and operation. Atmos. Meas. Tech., 9, 31313144, doi:10.5194/amt-9-3131-2016.

Baran, A. J., 2012: From the single-scattering properties of ice crystals to climate prediction: A way forward. Atmos. Res., 112, 45-69, doi:10.1016/j.atmosres.2012.04.010.

_- J.-F. Gayet, and V. Shcherbakov, 2012: On the interpretation of an unusual in-situ measured ice crystal scattering phase function. Atmos. Chem. Phys., 12, 9355-9364, doi:10.5194/ acp-12-9355-2012.

Baumgardner, D., H. Jonsson, W. Dawson, D. O'Connor, and R. Newton, 2001: The cloud, aerosol and precipitation spectrometer: A new instrument for cloud investigations. Atmos. Res., 59-60, 251-264, doi:10.1016/S0169-8095(01)00119-3.

——, R. Newton, M. Krämer, J. Meyer, A. Beyer, M. Wendisch, and P. Vochezer, 2014: The Cloud Particle Spectrometer with Polarization Detection (CPSPD): A next generation open-path cloud probe for distinguishing liquid cloud droplets from ice crystals. Atmos. Res., 142, 2-14, doi:10.1016/ j.atmosres.2013.12.010.

Cole, B., P. Yang, B. Baum, J. Riedi, and L. C.-Labonnote, 2014: Ice particle habit and surface roughness derived from parasol polarization measurements. Atmos. Chem. Phys., 14, 37393750, doi:10.5194/acp-14-3739-2014.

Connolly, P., C. Saunders, M. Gallagher, K. Bower, M. Flynn, T. Choularton, J. Whiteway, and R. Lawson, 2005: Aircraft observations of the influence of electric fields on the aggregation of ice crystals. Quart. J. Roy. Meteor. Soc., 131, 16951712, doi:10.1256/qj.03.217.

Crépel, O., J.-F. Gayet, J.-F. Fournol, and S. Oshchepkov, 1997: A new airborne polar nephelometer for the measurement of optical and microphysical cloud properties. Part II: Preliminary tests. Ann. Geophys., 15, 460-470, doi:10.1007/ s005850050460.

de Reus, M., and Coauthors, 2009: Evidence for ice particles in the tropical stratosphere from in-situ measurements. Atmos. Chem. Phys., 9, 6775-6792, doi:10.5194/acp-9-6775-2009.
Diskin, G. S., J. R. Podolske, G. W. Sachse, and T. A. Slate, 2002: Open-path airborne tunable diode laser hygrometer. Diode Lasers and Applications in Atmospheric Sensing, A. Fried, Ed., International Society for Optical Engineering (SPIE Proceedings, Vol. 4817), 196-204, doi:10.1117/12.453736.

Fahey, D., and Coauthors, 2014: The AquaVIT-1 intercomparison of atmospheric water vapor measurement techniques. Atmos. Meas. Tech., 7, 3159-3251, doi:10.5194/amtd-7-3159-2014.

Febvre, G., and Coauthors, 2009: On optical and microphysical characteristics of contrails and cirrus. J. Geophys. Res., 114, D02204, doi:10.1029/2008JD010184.

Frey, W., and Coauthors, 2011: In situ measurements of tropical cloud properties in the West African Monsoon: Upper tropospheric ice clouds, mesoscale convective system outflow, and subvisual cirrus. Atmos. Chem. Phys., 11, 5569-5590, doi:10.5194/acp-11-5569-2011.

Garrett, T. J., P. V. Hobbs, and H. Gerber, 2001: Shortwave, singlescattering properties of arctic ice clouds. J. Geophys. Res., 106, 15 155-15 172, doi:10.1029/2000JD900195.

Gayet, J.-F., G. Febvre, and H. Larsen, 1996: The reliability of the PMS FSSP in the presence of small ice crystals. J. Atmos. Oceanic Technol., 13, 1300-1310, doi:10.1175/ 1520-0426(1996)013<1300:TROTPF>2.0.CO;2.

— - O. Crépel, J. Fournol, and S. Oshchepkov, 1997: A new airborne polar nephelometer for the measurements of optical and microphysical cloud properties. Part I: Theoretical design. Ann. Geophys., 15, 451-459, doi:10.1007/ s00585-997-0451-1.

- S. Asano, A. Yamazaki, A. Uchiyama, A. Sinyuk, O. Jourdan, and F. Auriol, 2002: Two case studies of winter continental-type water and mixed-phase stratocumuli over the sea. 1: Microphysical and optical properties. J. Geophys. Res., 107, 4569, doi:10.1029/2001JD001106.

_ concentration of small chain-like aggregate ice crystals and large ice water contents near the top of a deep convective cloud during the CIRCLE-2 experiment. Atmos. Chem. Phys., 12, 727-744, doi:10.5194/acp-12-727-2012.

_- , and Coauthors, 2012b: The evolution of microphysical and optical properties of an A380 contrail in the vortex phase. Atmos. Chem. Phys., 12, 6629-6643, doi:10.5194/ acp-12-6629-2012.

Gerber, H., Y. Takano, T. J. Garrett, and P. V. Hobbs, 2000: Nephelometer measurements of the asymmetry parameter, volume extinction coefficient, and backscatter ratio in arctic clouds. J. Atmos. Sci., 57, 3021-3034, doi:10.1175/ 1520-0469(2000)057<3021:NMOTAP > 2.0.CO;2.

Giangrande, S. E., S. Collis, J. Straka, A. Protat, C. Williams, and S. Krueger, 2013: A summary of convective-core vertical velocity properties using ARM UHF wind profilers in Oklahoma. J. Appl. Meteor. Climatol., 52, 2278-2295, doi:10.1175/ JAMC-D-12-0185.1.

Heymsfield, A. J., and R. M. Sabin, 1989: Cirrus crystal nucleation by homogeneous freezing of solution droplets. J. Atmos. Sci., 46, 2252-2264, doi:10.1175/1520-0469(1989)046<2252: $\mathrm{CCNBHF}>2.0 . \mathrm{CO} ; 2$.

, L. M. Miloshevich, C. Schmitt, A. Bansemer, C. Twohy, M. R. Poellot, A. Fridlind, and H. Gerber, 2005: Homogeneous ice nucleation in subtropical and tropical convection and its influence on cirrus anvil microphysics. J. Atmos. Sci., 62, 41-64, doi:10.1175/JAS-3360.1.

_- A. Bansemer, G. Heymsfield, and A. O. Fierro, 2009: Microphysics of maritime tropical convective updrafts at 
temperatures from $20^{\circ}$ to $60^{\circ}$. J. Atmos. Sci., 66, 3530-3562, doi:10.1175/2009JAS3107.1.

Järvinen, E., O. Kemppinen, T. Nousiainen, T. Kociok, O. Möhler, T. Leisner, and M. Schnaiter, 2016: Laboratory investigations of mineral dust near-backscattering depolarization ratios. J. Quant. Spectrosc. Radiat. Transfer, 178, 192-208, doi:10.1016/ j.jqsrt.2016.02.003.

Jensen, E. J., O. B. Toon, H. B. Selkirk, J. D. Spinhirne, and M. R. Schoeberl, 1996: On the formation and persistence of subvisible cirrus clouds near the tropical tropopause. J. Geophys. Res., 101, 21 361-21 375, doi:10.1029/95JD03575.

Kärcher, B., and F. Yu, 2009: Role of aircraft soot emissions in contrail formation. Geophys. Res. Lett., 36, L01804, doi:10.1029/2008GL036649.

Kaye, P. H., E. Hirst, R. S. Greenaway, Z. Ulanowski, E. Hesse, P. J. DeMott, C. Saunders, and P. Connolly, 2008: Classifying atmospheric ice crystals by spatial light scattering. Opt. Lett., 33, 1545-1547, doi:10.1364/OL.33.001545.

Korolev, A. V., and G. Isaac, 2003: Roundness and aspect ratio of particles in ice clouds. J. Atmos. Sci., 60, 1795-1808, doi:10.1175/1520-0469(2003)060<1795:RAAROP > 2.0.CO;2.

_- M. P. Bailey, J. Hallett, and G. A. Isaac, 2004: Laboratory and in situ observation of deposition growth of frozen drops. J. Appl. Meteor., 43, 612-622, doi:10.1175/ 1520-0450(2004)043<0612:LAISOO > 2.0.CO;2.

Krämer, M., and Coauthors, 2009: Ice supersaturations and cirrus cloud crystal numbers. Atmos. Chem. Phys., 9, 3505-3522, doi:10.5194/acp-9-3505-2009.

Lawson, R. P., B. A. Baker, and B. L. Pilson, 2003: In-situ measurements of microphysical properties of mid-latitude and anvil cirrus. Proc. 30th Int. Symp. on Remote Sensing of Environment, Honolulu, HI, International Center for Remote Sensing of Environment, 707-710.

,,,--- and Q. Mo, 2006: In situ observations of the microphysical properties of wave, cirrus, and anvil clouds. Part II: Cirrus clouds. J. Atmos. Sci., 63, 3186-3203, doi:10.1175/ JAS3803.1.

- E. Jensen, D. L. Mitchell, B. Baker, Q. Mo, and B. Pilson, 2010: Microphysical and radiative properties of tropical clouds investigated in TC4 and NAMMA. J. Geophys. Res., 115, D00J08, doi:10.1029/2009JD013017.

Li, C., G. W. Kattawar, and P. Yang, 2004: Effects of surface roughness on light scattering by small particles. J. Quant. Spectrosc. Radiat. Transfer, 89, 123-131, doi:10.1016/ j.jqsrt.2004.05.016.

Lu, R.-S., G.-Y. Tian, D. Gledhill, and S. Ward, 2006: Grinding surface roughness measurement based on the co-occurrence matrix of speckle pattern texture. Appl. Opt., 45, 8839-8847, doi:10.1364/AO.45.008839.

Luebke, A., and Coauthors, 2016: The origin of midlatitude ice clouds and the resulting influence on their microphysical properties. Atmos. Chem. Phys., 16, 5793-5809, doi:10.5194/ acp-16-5793-2016.

May, P. T., J. H. Mather, G. Vaughan, C. Jakob, G. M. McFarquhar, K. N. Bower, and G. G. Mace, 2008: The Tropical Warm Pool International Cloud Experiment. Bull. Amer. Meteor. Soc., 89, 629-645, doi:10.1175/BAMS-89-5-629.

McFarquhar, G. M., and A. J. Heymsfield, 1996: Microphysical characteristics of three anvils sampled during the Central Equatorial Pacific Experiment. J. Atmos. Sci., 53, 2401-2423, doi:10.1175/1520-0469(1996)053<2401:MCOTAS > 2.0.CO;2.

— J. Um, M. Freer, D. Baumgardner, G. L. Kok, and G. Mace, 2007: Importance of small ice crystals to cirrus properties:
Observations from the Tropical Warm Pool International Cloud Experiment (TWP-ICE). Geophys. Res. Lett., 34, L13803, doi:10.1029/2007GL029865.

,-- , and R. Jackson, 2013: Small cloud particle shapes in mixed-phase clouds. J. Appl. Meteor. Climatol., 52, 1277-1293, doi:10.1175/JAMC-D-12-0114.1.

Meyer, J., 2012: Ice crystal measurements with the new particle spectrometer NIXE-CAPS. Schr. Forschungszent. Jülich, Reihe Umwelt/Environ., 160, 34 250-34 271.

Möhler, O., and Coauthors, 2003: Experimental investigation of homogeneous freezing of sulphuric acid particles in the aerosol chamber AIDA. Atmos. Chem. Phys., 3, 211-223, doi:10.5194/ acp-3-211-2003.

— , and Coauthors, 2008: The effect of organic coating on the heterogeneous ice nucleation efficiency of mineral dust aerosols. Environ. Res. Lett., 3, 025007, doi:10.1088/1748-9326/3/2/ 025007.

Nousiainen, T., and G. M. McFarquhar, 2004: Light scattering by quasi-spherical ice crystals. J. Atmos. Sci., 61, 2229-2248, doi:10.1175/1520-0469(2004)061<2229:LSBQIC>2.0.CO;2.

Ono, A., 1969: The shape and riming properties of ice crystals in natural clouds. J. Atmos. Sci., 26, 138-147, doi:10.1175/ 1520-0469(1969)026<0138:TSARPO > 2.0.CO;2.

Phillips, V. T., L. J. Donner, and S. T. Garner, 2007: Nucleation processes in deep convection simulated by a cloud-systemresolving model with double-moment bulk microphysics. J. Atmos. Sci., 64, 738-761, doi:10.1175/JAS3869.1.

Rosenfeld, D., and W. L. Woodley, 2000: Deep convective clouds with sustained supercooled liquid water down to $-37.5^{\circ} \mathrm{C}$. Nature, 405, 440-442, doi:10.1038/35013030.

Schnaiter, M., S. Büttner, O. Möhler, J. Skrotzki, M. Vragel, and R. Wagner, 2012: Influence of particle size and shape on the backscattering linear depolarisation ratio of small ice crystals-Cloud chamber measurements in the context of contrail and cirrus microphysics. Atmos. Chem. Phys., 12, $10465-$ 10 484, doi:10.5194/acp-12-10465-2012.

— , and Coauthors, 2016: Cloud chamber experiments on the origin of ice crystal surface roughness in cirrus clouds. Atmos. Chem. Phys., 16, 5091-5110, doi:10.5194/acp-16-5091-2016.

Schumann, U., 2005: Formation, properties and climatic effects of contrails. C. R. Phys., 6, 549-565, doi:10.1016/j.crhy.2005.05.002.

Stith, J. L., J. E. Dye, A. Bansemer, A. J. Heymsfield, C. A. Grainger, W. A. Petersen, and R. Cifelli, 2002: Microphysical observations of tropical clouds. J. Appl. Meteor., 41, 97-117, doi:10.1175/1520-0450(2002)041<0097:MOOTC >2.0.CO;2.

_ J. A. Haggerty, A. Heymsfield, and C. A. Grainger, 2004: Microphysical characteristics of tropical updrafts in clean conditions. J. Appl. Meteor., 43, 779-794, doi:10.1175/ 2104.1.

- and Coauthors, 2014: Ice particles in the upper anvil regions of midlatitude continental thunderstorms: the case for frozendrop aggregates. Atmos. Chem. Phys., 14, 1973-1985, doi:10.5194/ acp-14-1973-2014.

Ulanowski, Z., E. Hesse, P. H. Kaye, and A. J. Baran, 2006: Light scattering by complex ice-analogue crystals. J. Quant. Spectrosc. Radiat. Transfer, 100, 382-392, doi:10.1016/j.jqsrt.2005.11.052.

, P. Kaye, E. Hirst, and R. Greenaway, 2010: Light scattering by ice particles in the Earth's atmosphere and related laboratory measurements. Proc. 12th Int. Conf. on Electromagnetic and Light Scattering, Helsinki, Finland, University of Helsinki, 294-297.

_, E. Hirst, P. H. Kaye, and R. Greenaway, 2012: Retrieving the size of particles with rough and complex surfaces 
from two-dimensional scattering patterns. J. Quant. Spectrosc. Radiat. Transfer, 113, 2457-2464, doi:10.1016/j. jqsrt.2012.06.019.

, P. H. Kaye, E. Hirst, R. Greenaway, R. J. Cotton, E. Hesse, and C. T. Collier, 2014: Incidence of rough and irregular atmospheric ice particles from Small Ice Detector 3 measurements. Atmos. Chem. Phys., 14, 1649-1662, doi:10.5194/ acp-14-1649-2014.

Um, J., and G. M. McFarquhar, 2009: Single-scattering properties of aggregates of plates. Quart. J. Roy. Meteor. Soc., 135, 291-304, doi:10.1002/qj.378.

Vochezer, P., E. Järvinen, R. Wagner, P. Kupiszewski, T. Leisner, and M. Schnaiter, 2016: In situ characterization of mixed phase clouds using the Small Ice Detector and the Particle Phase Discriminator. Atmos. Meas. Tech., 9, 159177, doi:10.5194/amt-9-159-2016.

Voigt, C., and Coauthors, 2010: In-situ observations of young contrails-Overview and selected results from the concert campaign. Atmos. Chem. Phys., 10, 9039-9056, doi:10.5194/ acp-10-9039-2010.

- and Coauthors, 2016: ML-CIRRUS-The airborne experiment on natural cirrus and contrail cirrus with the highaltitude long-range research aircraft HALO. Bull. Amer. Meteor. Soc., doi:10.1175/BAMS-D-15-00213.1, in press.
Wagner, R., C. Linke, K.-H. Naumann, M. Schnaiter, M. Vragel, M. Gangl, and H. Horvath, 2009: A review of optical measurements at the aerosol and cloud chamber AIDA. J. Quant. Spectrosc. Radiat. Transfer, 110, 930-949, doi:10.1016/ j.jqsrt.2009.01.026.

Wendisch, M., and Coauthors, 2016: The ACRIDICON-CHUVA campaign: Studying tropical deep convective clouds and precipitation over Amazonia using the new German research aircraft HALO. Bull. Amer. Meteor. Soc., doi:10.1175/ BAMS-D-14-00255.1, in press.

Yang, P., B. A. Baum, A. J. Heymsfield, Y. X. Hu, H.-L. Huang, S.-C. Tsay, and S. Ackerman, 2003: Single-scattering properties of droxtals. J. Quant. Spectrosc. Radiat. Transfer, 79-80, 1159-1169, doi:10.1016/S0022-4073(02)00347-3.

— , G. W. Kattawar, G. Hong, P. Minnis, and Y. Hu, 2008: Uncertainties associated with the surface texture of ice particles in satellite-based retrieval of cirrus clouds-Part I: Singlescattering properties of ice crystals with surface roughness. IEEE Trans. Geosci. Remote Sens., 46, 1940-1947, doi:10.1109/ TGRS.2008.916471.

Yi, B., P. Yang, B. A. Baum, T. L'Ecuyer, L. Oreopoulos, E. J. Mlawer, A. J. Heymsfield, and K.-N. Liou, 2013: Influence of ice particle surface roughening on the global cloud radiative effect. J. Atmos. Sci., 70, 2794-2807, doi:10.1175/JAS-D-13-020.1. 